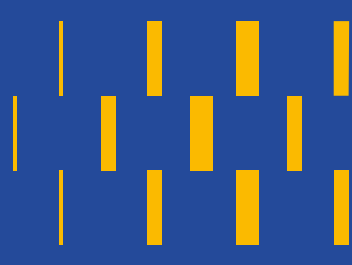

\title{
Minería y metalurgia prehispánica en el Noroeste Argentino: una puesta al día de las evidencias arqueológicas recuperadas en la actual provincia de Jujuy
}

\section{Pre-Columbian Mining and metallurgy in the Argentinean Northwest: an update of the archaeological evidences recovered in the present-day Jujuy province}

\author{
Carlos Ignacio Angiorama1,2 (D) https://orcid.org/0000-0001-5153-6938 \\ María Florencia Becerra ${ }^{1,3}$ (D) https://orcid.org/0000-0001-6302-7452 \\ ${ }^{1}$ Consejo Nacional de Investigaciones Científicas y Técnicas, ARGENTINA. \\ ${ }^{2}$ Instituto Superior de Estudios Sociales, Universidad Nacional de Tucumán, Facultad de Ciencias Naturales \\ e IML, Instituto de Arqueología y Museo / San Miguel de Tucumán, ARGENTINA. \\ Email: carlosangiorama@gmail.com \\ ${ }^{3}$ Universidad de Buenos Aires, Facultad de Filosofía y Letras, Instituto de Arqueología, Ciudad Autónoma \\ de Buenos Aires, ARGENTINA. Email: florenciabecerra@gmail.com
}

\section{Resumen}

Presentamos una síntesis de lo que conocemos hasta el momento sobre las actividades mineras y metalúrgicas prehispánicas desarrolladas en el territorio de la actual provincia de Jujuy (Argentina). Para ello, se analizan los contextos extractivos y productivos estudiados por nosotros y por otros investigadores en las tres ecorregiones de la provincia, y se identifican las evidencias mineras directas e indirectas, y los indicadores de fundición y manufactura de objetos metálicos. Sobre la base de los resultados alcanzados se afirma que más allá de la disponibilidad de minerales metalíferos en la provincia, las actividades mineras prehispánicas no adquirieron una gran escala ni en extensión ni intensidad, y se habrían desarrollado fundamentalmente en la puna y en un sector de las sierras subandinas. Las evidencias de producción metalúrgica están presentes tanto en la puna como en la cordillera Oriental, especialmente en la quebrada de $\mathrm{Hu}$ mahuaca. Las mismas datan de tiempos preincaicos tardíos (segundo milenio DC) e incaicos y muestran el procesamiento de oro, plata, cobre y estańo y sus aleaciones, y el consumo de objetos metálicos en contextos diversos. La conquista incaica habría generado ciertos cambios en la organización y en el acceso a materias primas, pero no en las técnicas de producción.

Palabras clave: actividades extractivas, minerales, Período Inca, tiempos preincaicos. 


\begin{abstract}
This paper synthetizes what we know so far about pre-Columbian mining and metallurgical activities, during pre-Inka and Inka times, in the present-day territory of Jujuy province (Argentina). To do so, we analyze the extractive and productive contexts that we and other scholars have studied in the three eco-regions of the province, in order to identify the direct and indirect evidences of mining, smelting and manufacture of metal objects. Based on the results, we state that despite the availability of metalliferous minerals in the province, the preColumbian mining activities have not reached a large scale, neither in extent nor in intensity, and they would have been carried out mainly in the puna and in an area of the Sierras subandinas. There is evidence of metallurgical production in the puna as well as in the cordillera Oriental, especially in the quebrada de Humahuaca, which dates from pre-inka Late period (second millennium AD) and Inka times and shows the use of gold, silver, copper, tin and their alloys, and the consumption of metallic artefacts in diverse contexts. The Inka conquest would have generated certain modifications in the organization and access of raw materials, but not in the production techniques.
\end{abstract}

Keywords: extractive activities, minerals, Inka Period, Pre-Inka Period.

Recibido: 20 septiembre 2020. Aceptado: 25 enero 2021 


\section{Introducción}

El área andina albergó una tradición minero-metalúrgica prehispánica muy importante, de gran profundidad temporal, y vinculada íntimamente con aspectos simbólico-religiosos y políticos de las sociedades que la habitaron (Lechtman, 1984). Dentro de ella, el actual Noroeste Argentino (NOA) es considerado un área de innovación y desarrollo (González, 2004), y cuenta con una de las evidencias más antiguas de trabajo en cobre (Scattolin, Bugliani, Cortés, Pereyera Domingorena y Calo, 2010). Asimismo, la presencia de yacimientos minerales metalíferos y la destreza de los metalurgistas locales para procesarlos han sido considerados dos de los motivos de su anexión al Imperio inca en el siglo XV DC (Raffino, 1978; González, 2004). El territorio de la actual provincia de Jujuy se destaca especialmente en el NOA tanto por la gran cantidad y variedad de objetos de metal de diversa cronología hallados en sitios arqueológicos ubicados en sus distintos ambientes como por su enorme riqueza en minerales metalíferos. Entre los recursos disponibles se encuentran importantes fuentes de oro, plata, cobre y estaño, los principales cuatro metales utilizados en los Andes del Sur durante tiempos prehispánicos.

La metalurgia andina, y del NOA en particular, ha sido abordada especialmente a partir del estudio de la diversidad, la complejidad y la cantidad de bienes metálicos producidos y usados por sus sociedades, mientras que las evidencias indiscutibles de minería prehispánica identificadas son aún, en comparación, escasas (Salazar, 2003-2004). De hecho, los estudios de las prácticas mineras que han predominado se han basado, de acuerdo con Salazar y Vilches (2014), en abordajes indirectos, es decir, a partir de evidencias etnohistóricas, toponímicas, geológicas o de contextos arqueológicos con presencia de minerales y/o artefactos mineros. Los estudios "directos" del registro arqueológico en sitios mineros son menos abundantes, en parte por la dificultad de encontrar evidencias de actividades extractivas que hayan sobrevivido a posteriores explotaciones mineras de mediana y gran escala, o que puedan ser asignadas con seguridad a momentos prehispánicos (Salazar, 2003-2004). A pesar de estas limitaciones, debe señalarse que desde los primeros intentos en la década del setenta llevados adelante por Lechtman (1976) en Perú, y especialmente en los últimos años, se han logrado avances en el conocimiento de las actividades extractivas prehispánicas con la identificación de contextos mineros de distinta cronología y dedicados a minerales metalíferos y no metalíferos (Salazar y Vilches, 2014). Asimismo, en cuanto a la tecnología metalúrgica, las investigaciones recientes han permitido obtener un panorama mucho más diverso del que se había asumido a partir de la lectura de los cronistas y de la documentación colonial (entre otros, Vetter, Casagrande, Vásquez y Fulle, 2008; Lechtman, Cruz, Macfarlane y Carter, 2010; Salazar, Berenguer y Vega, 2013; Spina, Giovanetti y Ferraris, 2017; Figueroa et al., 2018).

En este artículo, y luego de dos décadas de trabajo, nos proponemos realizar una puesta al día de lo que se conoce hasta el momento acerca de las actividades mineras y metalúrgicas llevadas a cabo durante momentos prehispánicos en el territorio de lo que es hoy la provincia de Jujuy, prestando especial atención a los contextos productivos, detallando tanto las evidencias mineras directas e indirectas detectadas como las de fundición y manufactura de objetos metálicos. En este sentido, analizaremos en conjunto los resultados de investigaciones propias y de otros autores desarrolladas en las distintas ecorregiones del área de estudio, reevaluando las interpretaciones previas, especialmente aquellas vinculadas con el desarrollo de actividades minero-metalúrgicas durante el período de dominación inca de este territorio. 


\section{Ambientes y recursos mineros de la provincia de Jujuy}

De acuerdo con sus características geológicas, geomorfológicas y climáticas, la provincia de Jujuy, localizada en el extremo noroccidental de la República Argentina, puede dividirse en tres ecorregiones que, de oeste a este, son (1) la puna, (2) la cordillera Oriental y los valles interserranos, y (3) las sierras subandinas, que incluyen un sector de planicies pedemontanas subandinas (Pereyra, 2008) (Figura 1). La puna constituye parte del extremo sur del altiplano andino, con alturas superiores a $3600 \mathrm{msnm}$ y clima árido y frío. La región contigua incluye las sierras de Santa Victoria, Zenta y Chañi, como también la quebrada de Humahuaca, un valle con dirección norte-sur y cuya altura varía entre 3400 y 2000 msnm, y que constituye una vía natural de acceso y comunicación entre la puna, las sierras subandinas y el piedemonte (Lapido y Gabaldón, 1998). La quebrada de Humahuaca, en comparación con las otras ecorregiones de la provincia, ha sido la más estudiada desde el punto de vista arqueológico. Las sierras subandinas forman una faja alargada en sentido longitudinal, donde destacan las sierras de Calilegua, Valle Grande, Zapla, Santa Bárbara, Centinela y Maíz Gordo, cuyas alturas varían entre los 3000 y $4000 \mathrm{msnm}$, decreciendo hacia el este y con valles de gran pendiente. Esta ecorregión incluye las provincias fitogeográficas de las Yungas (selvas de transición, selvas y bosques montanos) y Chaqueña, con altitudes generalmente entre los 1500 y los $500 \mathrm{msnm}$ y climas templados o cálidos y húmedos (Cabrera, 1994; Pereyra, 2008).

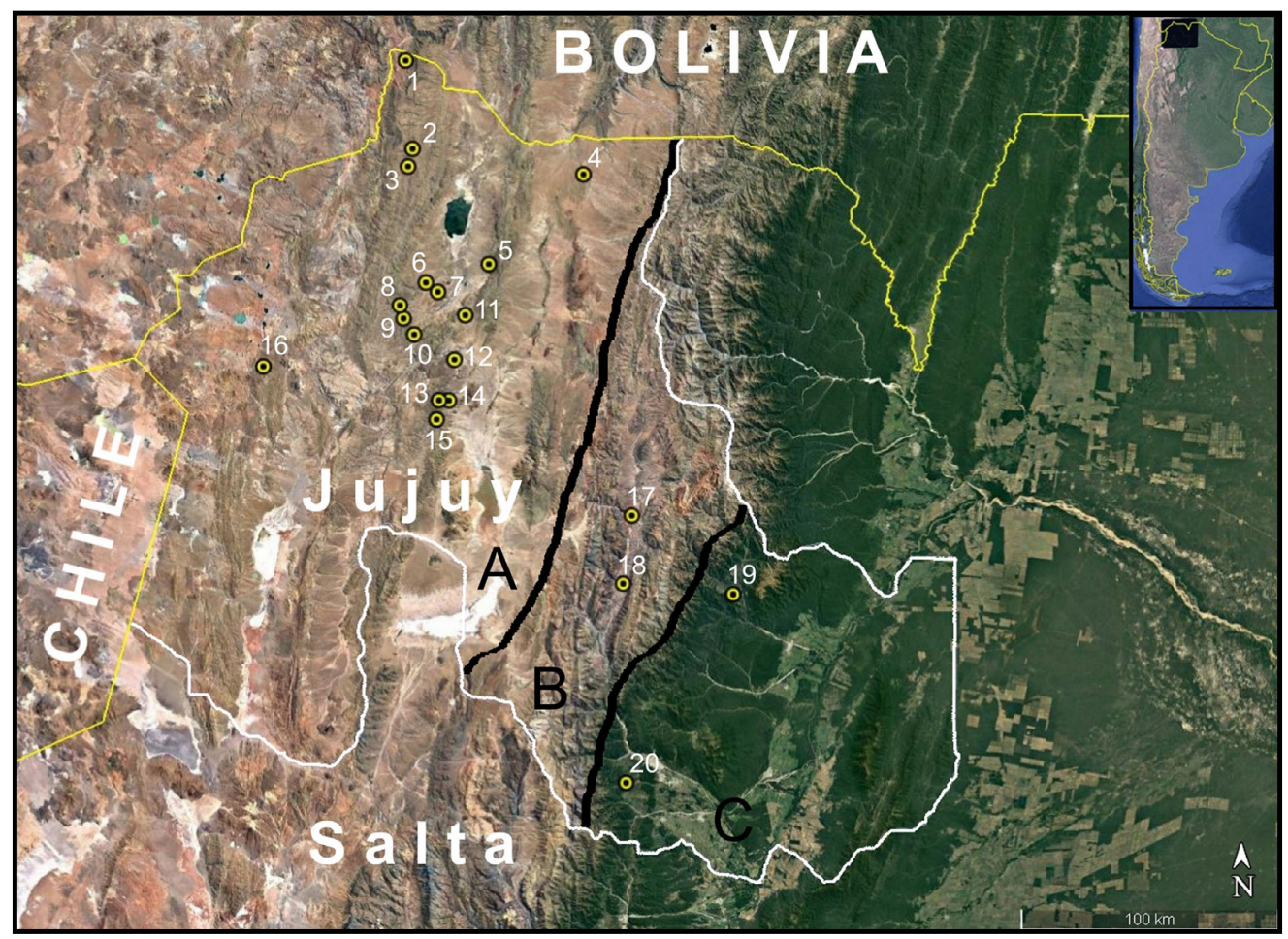

Figura 1. Mapa de ubicación de los sitios mencionados en el texto.

a) Ecorregión puna; b) Ecorregión cordillera Oriental; c) Ecorregión sierras subandinas.

1) Finispatriae; 2) Pueblo Viejo de Oratorio; 3) Timón Cruz 2; 4) Sansana; 5) Moreta; 6) Pukara de Rinconada; 7) Pan de Azúcar; 8) San José; 9) Chajarahuayco 25; 10) Tabladitas 1;

11) Queta; 12) Doncellas; 13) Casabindo; 14) Ojo de Agua; 15) Pueblo Viejo de Tucute; 16) Rosario de Coyahuayma; 17) Los Amarillos; 18) Pukara de Tilcara; 19) Cerro Fundición; 20) La Almona. 
En cuanto a los yacimientos minerales de la provincia, sabemos que las fuentes de cobre aprovechables mediante técnicas conocidas en la antigüedad se distribuyen en todas las ecorregiones mencionadas. Lo hacen en forma de vetas, mantos y bolsones, como estado nativo en ciertos casos, pero con mayor frecuencia como calcopirita, bornita y calcosina (sulfuros), malaquita y azurita (carbonatos), y crisocola (silicato). Las fuentes de plata en veta y de oro en placeres aluviales y en veta están presentes fundamentalmente en la puna, pero también existen algunas en la ecorregión de sierras subandinas. A diferencia del resto de los elementos mencionados, los yacimientos de estańo, principalmente pequeńos depósitos vetiformes y grandes acumulaciones aluvionales, productos de la erosión de los primeros, son exclusivos de la puna. El estaño se presenta más frecuentemente como casiterita (óxido), pero también como estannita y hexaestannita (sulfuros) (Angiorama, 2001, 2003; Sureda, Ruiz, Ramírez y Quiroga, 2008).

\section{Las actividades mineras en tiempos prehispánicos}

A pesar de que en el actual territorio de la provincia de Jujuy, como hemos dicho, se localizan importantes yacimientos minerales que podrían haber sido explotados en momentos prehispánicos, la información arqueológica disponible sobre actividades mineras correspondientes a este período es escasa, y en la mayoría de los casos la asignación temporal de las evidencias está dada únicamente por su cercanía espacial con ocupaciones prehispánicas que, en realidad, podrían haber estado o no vinculadas a las explotaciones. La identificación de trabajos mineros coloniales puede ser, por una parte, un indicador de que dichos yacimientos pudieron haber sido conocidos y explotados en momentos previos pero, por otra, el impacto producido por esas actividades extractivas dificulta en gran medida la detección de evidencias asignables con seguridad a momentos precolombinos. Como vemos en la Tabla 1, en Jujuy se han identificado una gran cantidad de minas con distintos tipos de evidencias de labores antiguas y diversas estructuras residenciales asociadas, la mayoría de las cuales se localizan en la Puna y son asignables a momentos coloniales. Algunas de ellas, como detallaremos aquí, podrían remontarse también a momentos prehispánicos.

Para la ecorregión de las sierras subandinas, donde se encuentran yacimientos de cobre, plata y oro (Angiorama, 2001), lo único que conocemos hasta el momento son los hallazgos de evidencias de explotación minera prehispánica registrados por Cruz (2010) en el cerro Fundición, en Calilegua. Allí, en un espacio pequeño, se identificaron tres tipos de explotaciones: siete minas en galería, cinco en pozo vertical y tres a cielo abierto. Las huellas de trabajo observadas en las paredes de una de las galerías indican el desprendimiento de la roca por aplicación directa de fuego y el uso de punzones, muy probablemente de asta de taruca (Hippocamelus antisensis), para la extracción de minerales ricos en cobre y plomo argentífero. Teniendo en cuenta la ausencia de rastros de uso de barreno y de materiales asignables a momentos coloniales y/o republicanos, estas evidencias indicarían, de acuerdo con este investigador, la existencia en el lugar de explotaciones prehispánicas (Cruz, 2010). Asimismo, en una de las minas en pozo, Cruz observó que su entrada había sido tapada intencionalmente con rocas, lo que interpreta como una manera de ocultar los trabajos de explotación realizados. Al pie del cerro se halló un molino semejante a un maray para el procesamiento de los minerales extraídos. Aunque resulta significativa la ausencia de evidencias de actividades metalúrgicas en el área de explotación, habría tenido lugar allí el tostado de los minerales. Estas explotaciones habrían estado comunicadas por un camino con el sitio de habitación Pueblito y con el adoratorio de altura del cerro Amarillo, ambos asignables a la ocupación inca de la región (siglo XV DC). En momentos coloniales (siglo XVI a inicios del siglo XIX DC) no se habría continuado con 
las actividades mineras en Calilegua, probablemente por las dificultades de acceso y la resistencia de los chiriguanos a los españoles en la región (Cruz, 2010). No existe tampoco hasta el momento información arqueológica que dé cuenta de la existencia de actividades mineras coloniales en otras áreas de esta ecorregión, aunque sí sabemos de la solicitud del indio Joseph Colquivanca/Colquibanba de un permiso para la explotación de unas minas de plata en el cerro Paño de Cabeza en el año 1697, a partir del hallazgo de "unos rodados que al parecer tienen plata". ${ }^{1}$ Según Ferreiro (2015), este cerro se localizaría en la actual La Almona, en el departamento Doctor Manuel Belgrano de la provincia de Jujuy.

Tabla 1. Yacimientos metalíferos con evidencias de actividades minero-metalúrgicas y/o estructuras residenciales asociadas asignables a momentos coloniales.

\begin{tabular}{|c|c|c|c|c|c|c|c|c|c|c|c|c|c|c|c|}
\hline \multirow[b]{2}{*}{ 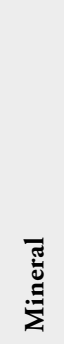 } & \multirow[b]{2}{*}{ 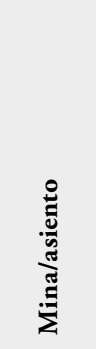 } & \multicolumn{7}{|c|}{ Evidencias minero-metalúrgicas } & \multicolumn{3}{|c|}{$\begin{array}{c}\text { Estructuras } \\
\text { de habitación } \\
\text { asociadas }\end{array}$} & \multirow{2}{*}{ 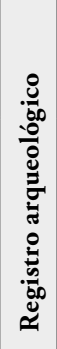 } & \multirow{2}{*}{ 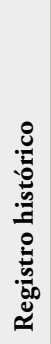 } & \multirow{2}{*}{ 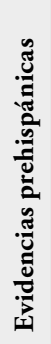 } & \multirow{2}{*}{ 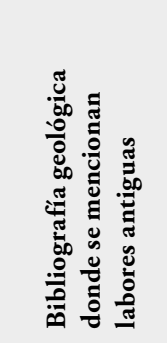 } \\
\hline & & $\frac{g}{\tilde{\theta}}$ & ڤ్ & 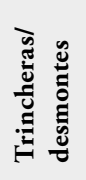 & 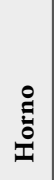 & 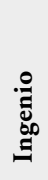 & 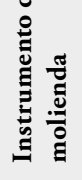 & Ũ & 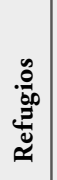 & 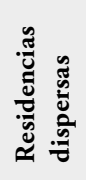 & $\begin{array}{l}\frac{0}{\pi} \\
\frac{\pi}{0} \\
\stackrel{0}{0}\end{array}$ & & & & \\
\hline \multicolumn{16}{|c|}{ Sierras subandinas } \\
\hline $\mathrm{Cu}$ & $\begin{array}{c}\text { Cerro } \\
\text { Fundi- } \\
\text { ción, } \\
\text { Calile- } \\
\text { gua* }^{*}\end{array}$ & $\mathrm{X}$ & & $\mathrm{X}$ & & & $\mathrm{X}$ & & & & & & & $\mathrm{X}$ & \\
\hline $\mathrm{Ag}$ & $\begin{array}{c}\text { Cerro } \\
\text { Paño } \\
\text { de } \\
\text { Cabe- } \\
\text { za, La } \\
\text { Al- } \\
\text { mona, } \\
\text { Doctor } \\
\text { Manuel } \\
\text { Belgra- } \\
\text { no }\end{array}$ & & & & & & & & & & & & $\mathrm{X}$ & & \\
\hline \multicolumn{16}{|c|}{ Puna } \\
\hline $\begin{array}{l}\mathrm{Ag} \\
\mathrm{Pb} \mathrm{y} \\
\mathrm{Zn}\end{array}$ & $\begin{array}{c}\text { El } \\
\text { Agui- } \\
\text { lar, } \\
\text { Huma- } \\
\text { huaca }\end{array}$ & & & & $\mathrm{X}$ & & & & & & & & $\mathrm{X}$ & & Méndez, 1999 \\
\hline $\begin{array}{c}\text { Au y } \\
\text { Sn }\end{array}$ & $\begin{array}{l}\text { Aje- } \\
\text { drez, } \\
\text { Rinco- } \\
\text { nada }\end{array}$ & $\mathrm{X}$ & $\mathrm{X}$ & $\mathrm{X}$ & & & & $\mathrm{X}$ & & & $\mathrm{X}$ & $\mathrm{X}$ & $\mathrm{X}$ & & $\begin{array}{c}\text { Brackebusch, } \\
\text { 1883/1981; } \\
\text { Jutorán, } 1958\end{array}$ \\
\hline
\end{tabular}

1 Archivo de Tribunales de Jujuy, Carpeta 23. Leg. 709 Paño de Cabeza, Ańo 1697. 
Minería y metalurgia prehispánica en el Noroeste Argentino: una puesta al día de las evidencias...

\begin{tabular}{|c|c|c|c|c|c|c|c|c|c|c|c|c|c|c|c|}
\hline $\mathrm{Au}$ & $\begin{array}{c}\text { Pam- } \\
\text { pacoya, } \\
\text { Rinco- } \\
\text { nada }\end{array}$ & $\mathrm{X}$ & & $\mathrm{X}$ & & & & & & $\mathrm{X}$ & & & $\mathrm{X}$ & & $\begin{array}{l}\text { Cabanettes y } \\
\text { Amans, } 1891\end{array}$ \\
\hline $\mathrm{Au}$ & $\begin{array}{c}\text { Caba- } \\
\text { longa, } \\
\text { Rinco- } \\
\text { nada }\end{array}$ & $X$ & $\mathrm{X}$ & $\mathrm{X}$ & $\mathrm{X}$ & & & & & & & & & & $\begin{array}{l}\text { Cabanettes y } \\
\text { Amans, } 1891\end{array}$ \\
\hline $\mathrm{Au}$ & $\begin{array}{c}\text { El } \\
\text { Cón- } \\
\text { dor, } \\
\text { Rinco- } \\
\text { nada }\end{array}$ & & X & $\mathrm{X}$ & & & & & & & & & & & $\begin{array}{c}\text { Cabanettes y } \\
\text { Amans, 1891; } \\
\text { Zappettini, } \\
2004\end{array}$ \\
\hline $\mathrm{Au}$ & $\begin{array}{l}\text { El Car- } \\
\text { men, } \\
\text { Rinco- } \\
\text { nada }\end{array}$ & & X & X & & & & & & & & & $\mathrm{X}$ & & $\begin{array}{c}\text { Kittl, } 1925 \text { en } \\
\text { Zappettini, } \\
\text { 2004; Cabanet- } \\
\text { tes y Amans, } \\
1891\end{array}$ \\
\hline $\mathrm{Au}$ & $\begin{array}{c}\text { Laguna } \\
\text { Pampa } \\
\text { Colo- } \\
\text { rada 1, } \\
\text { Rinco- } \\
\text { nada }\end{array}$ & & & X & & & & & $X$ & & & $X$ & & & \\
\hline $\mathrm{Au}$ & $\begin{array}{c}\text { Cabe- } \\
\text { cera } \\
\text { de Río } \\
\text { He- } \\
\text { rrana, } \\
\text { Rinco- } \\
\text { nada }\end{array}$ & & & $\mathrm{X}$ & & & & & $\mathrm{X}$ & & & $X$ & & & \\
\hline $\mathrm{Au}$ & $\begin{array}{l}\text { Río Lo- } \\
\text { piara, } \\
\text { Rinco- } \\
\text { nada }\end{array}$ & & & $X$ & & & & & X & & & $\mathrm{X}$ & & & \\
\hline $\mathrm{Au}$ & $\begin{array}{c}\text { Jara } \\
\text { Lomas, } \\
\text { Rinco- } \\
\text { nada }\end{array}$ & & & $X$ & & & & & $X$ & & & $X$ & & & \\
\hline $\mathrm{Au}$ & $\begin{array}{c}\text { San } \\
\text { José, } \\
\text { Rinco- } \\
\text { nada }\end{array}$ & & & $X$ & & & & & X & & & $X$ & & $X$ & \\
\hline $\mathrm{Au}$ & $\begin{array}{c}\text { Santo } \\
\text { Do- } \\
\text { mingo, } \\
\text { Rinco- } \\
\text { nada }\end{array}$ & & $X$ & X & & & $X$ & $X$ & $X$ & & $X$ & $X$ & $\mathrm{X}$ & & $\begin{array}{l}\text { Cabanettes y } \\
\text { Amans, } 1891\end{array}$ \\
\hline $\mathrm{Ag}$ & $\begin{array}{c}\text { Cochi- } \\
\text { nocal } \\
\text { Queta, } \\
\text { Cochi- } \\
\text { noca }\end{array}$ & & & & & $\mathrm{X}$ & & & & & & & $\mathrm{X}$ & & \\
\hline
\end{tabular}




\begin{tabular}{|c|c|c|c|c|c|c|c|c|c|c|c|c|c|c|}
\hline $\begin{array}{l}\mathrm{Pb} \\
\mathrm{Zny} \\
\mathrm{Ag}\end{array}$ & $\begin{array}{l}\text { Pan de } \\
\text { Azúcar, } \\
\text { Rinco- } \\
\text { nada }\end{array}$ & & $\mathrm{X}$ & & $\mathrm{X}$ & & & & & $\mathrm{X}$ & $\mathrm{X}$ & $\mathrm{X}$ & $\mathrm{X}$ & $\begin{array}{c}\text { Andrews, } \\
\text { 1825/1967; Ca- } \\
\text { talano, } 2004\end{array}$ \\
\hline $\begin{array}{l}\mathrm{Auy} \\
\mathrm{Pb} / \\
\mathrm{Ag}\end{array}$ & $\begin{array}{c}\text { Chaja- } \\
\text { rahuai- } \\
\text { co, } \\
\text { Rinco- } \\
\text { nada }\end{array}$ & & & & $\mathrm{X}$ & & & & $\mathrm{X}$ & & $\mathrm{X}$ & & $\mathrm{X}$ & \\
\hline $\mathrm{Au}$ & $\begin{array}{c}\text { Gua- } \\
\text { dalupe, } \\
\text { Rinco- } \\
\text { nada }\end{array}$ & & & $\mathrm{X}$ & & & & & & & & $\mathrm{X}$ & & $\begin{array}{l}\text { Cabanettes y } \\
\text { Amans, } 1891\end{array}$ \\
\hline $\mathrm{Au}$ & $\begin{array}{c}\text { San } \\
\text { Joseph } \\
\text { de los } \\
\text { Uros, } \\
\text { Rinco- } \\
\text { nada }\end{array}$ & & & & & & & & & & & $\mathrm{X}$ & & \\
\hline $\begin{array}{l}\mathrm{Sn}, \\
\mathrm{Au} \mathrm{y} \\
\mathrm{Ag}\end{array}$ & $\begin{array}{l}\text { Pir- } \\
\text { quitas, } \\
\text { Rinco- } \\
\text { nada }\end{array}$ & $\mathrm{X}$ & $\mathrm{X}$ & & X & & & & & & & & & Catalano, 2004 \\
\hline $\begin{array}{l}\mathrm{Pb} y \\
\mathrm{Ag}\end{array}$ & $\begin{array}{c}\text { Casa- } \\
\text { blanca, } \\
\text { Rinco- } \\
\text { nada }\end{array}$ & & & & $\mathrm{X}$ & & $X$ & $\mathrm{X}$ & & & X & & & \\
\hline $\mathrm{Au}$ & $\begin{array}{l}\text { Naza- } \\
\text { reno, } \\
\text { Rinco- } \\
\text { nada }\end{array}$ & & $X$ & $X$ & & & & & & & & $\mathrm{X}$ & & $\begin{array}{l}\text { Cabanettes y } \\
\text { Amans, } 1891\end{array}$ \\
\hline $\mathrm{Au}$ & $\begin{array}{c}\text { San } \\
\text { José de } \\
\text { la Rin- } \\
\text { conada, } \\
\text { Rinco- } \\
\text { nada }\end{array}$ & $\mathrm{X}$ & $\mathrm{X}$ & $\mathrm{X}$ & & & $\mathrm{X}$ & & & $\mathrm{X}$ & $\mathrm{X}$ & $\mathrm{X}$ & & $\begin{array}{l}\text { Cabanettes y } \\
\text { Amans, } 1891\end{array}$ \\
\hline $\begin{array}{l}\mathrm{Pb} \\
\mathrm{Zny} \\
\mathrm{Ag}\end{array}$ & $\begin{array}{l}\text { Chin- } \\
\text { chillas, } \\
\text { Rinco- } \\
\text { nada }\end{array}$ & $\mathrm{X}$ & $\mathrm{X}$ & & $\mathrm{X}$ & & & $\mathrm{X}$ & & & $\mathrm{X}$ & & & $\begin{array}{c}\text { Cabanettes y } \\
\text { Amans, 1891, } \\
\text { p. 40; Hóskold, } \\
1889\end{array}$ \\
\hline $\mathrm{Au}$ & $\begin{array}{c}\text { Rosario } \\
\text { de Co- } \\
\text { yahua- } \\
\text { yma, } \\
\text { Rinco- } \\
\text { nada }\end{array}$ & & $\mathrm{X}$ & $\mathrm{X}$ & & $\mathrm{X}$ & & & $\mathrm{X}$ & & X & & X & $\begin{array}{l}\text { Cabanettes y } \\
\text { Amans, 1891; } \\
\text { Sgrosso, } 1943\end{array}$ \\
\hline $\mathrm{Ag}$ & $\begin{array}{c}\text { Cerro } \\
\text { Gra- } \\
\text { nada, } \\
\text { Rinco- } \\
\text { nada }\end{array}$ & & $\mathrm{X}$ & & & & & & & & & & & $\begin{array}{l}\text { Cabanettes y } \\
\text { Amans, } 1891\end{array}$ \\
\hline
\end{tabular}


Minería y metalurgia prehispánica en el Noroeste Argentino: una puesta al día de las evidencias...

\begin{tabular}{|c|c|c|c|c|c|c|c|c|c|c|c|c|c|c|}
\hline $\mathrm{Au}$ & $\begin{array}{c}\text { Anti- } \\
\text { guyo, } \\
\text { Rinco- } \\
\text { nada }\end{array}$ & $\mathrm{X}$ & $\mathrm{X}$ & $\mathrm{X}$ & & & $\mathrm{X}$ & & & $\mathrm{X}$ & $\mathrm{X}$ & X & & $\begin{array}{l}\text { Cabanettes y } \\
\text { Amans, } 1891\end{array}$ \\
\hline $\begin{array}{c}\mathrm{Pb}, \\
\mathrm{Zny} \\
\mathrm{Ag}\end{array}$ & $\begin{array}{c}\text { Choca- } \\
\text { ya/Ra- } \\
\text { chaite, } \\
\text { Cochi- } \\
\text { noca }\end{array}$ & & $\mathrm{X}$ & & & & & & & & & & & $\begin{array}{l}\text { Alonso, 2011; } \\
\text { Coira et al., } \\
2004\end{array}$ \\
\hline $\begin{array}{c}\mathrm{Au} \mathrm{y} \\
\mathrm{Cu}\end{array}$ & $\begin{array}{c}\text { Eureka, } \\
\text { Santa } \\
\text { Cata- } \\
\text { lina }\end{array}$ & & $\mathrm{X}$ & & & & $x$ & & & & $\mathrm{X}$ & $X$ & & Alonso, 2010 \\
\hline $\mathrm{Au}$ & $\begin{array}{c}\text { San } \\
\text { Ber- } \\
\text { nardo, } \\
\text { Santa } \\
\text { Cata- } \\
\text { lina }\end{array}$ & & & & & & & & & & & $\mathrm{X}$ & & \\
\hline $\mathrm{Au}$ & $\begin{array}{l}\text { San } \\
\text { Fran- } \\
\text { cisco, } \\
\text { Santa } \\
\text { Cata- } \\
\text { lina }\end{array}$ & $\mathrm{x}$ & $\mathrm{X}$ & $\mathrm{X}$ & & $X$ & & & $x$ & & $\mathrm{X}$ & & & \\
\hline $\mathrm{Au}$ & $\begin{array}{c}\text { Los } \\
\text { Azules, } \\
\text { Santa } \\
\text { Cata- } \\
\text { lina }\end{array}$ & & & $\mathrm{X}$ & & & & $\mathrm{X}$ & & & $\mathrm{X}$ & $X$ & & Sgrosso, 1943 \\
\hline $\mathrm{Au}$ & $\begin{array}{c}\text { Cori- } \\
\text { pampa, } \\
\text { Santa } \\
\text { Cata- } \\
\text { lina }\end{array}$ & & & $\mathrm{X}$ & & & & $\mathrm{X}$ & & & $\mathrm{X}$ & & & \\
\hline $\mathrm{Au}$ & $\begin{array}{l}\text { Ora- } \\
\text { torio, } \\
\text { Santa } \\
\text { Cata- } \\
\text { lina }\end{array}$ & $\mathrm{X}$ & & $\mathrm{X}$ & & $X$ & & & $X$ & $\mathrm{X}$ & $\mathrm{X}$ & & $\mathrm{X}$ & \\
\hline $\mathrm{Au}$ & $\begin{array}{c}\text { Timón } \\
\text { Cruz, } \\
\text { Santa } \\
\text { Cata- } \\
\text { lina }\end{array}$ & & $\mathrm{X}$ & $\mathrm{X}$ & & $X$ & & $\mathrm{X}$ & $X$ & & $\mathrm{X}$ & $\mathrm{X}$ & $\mathrm{X}$ & \\
\hline $\mathrm{Au}$ & $\begin{array}{l}\text { San } \\
\text { Isidro, } \\
\text { Santa } \\
\text { Cata- } \\
\text { lina }\end{array}$ & & & & $\mathrm{X}$ & & & & & & & $\mathrm{X}$ & & $\begin{array}{l}\text { Cabanettes y } \\
\text { Amans, } 1891\end{array}$ \\
\hline
\end{tabular}




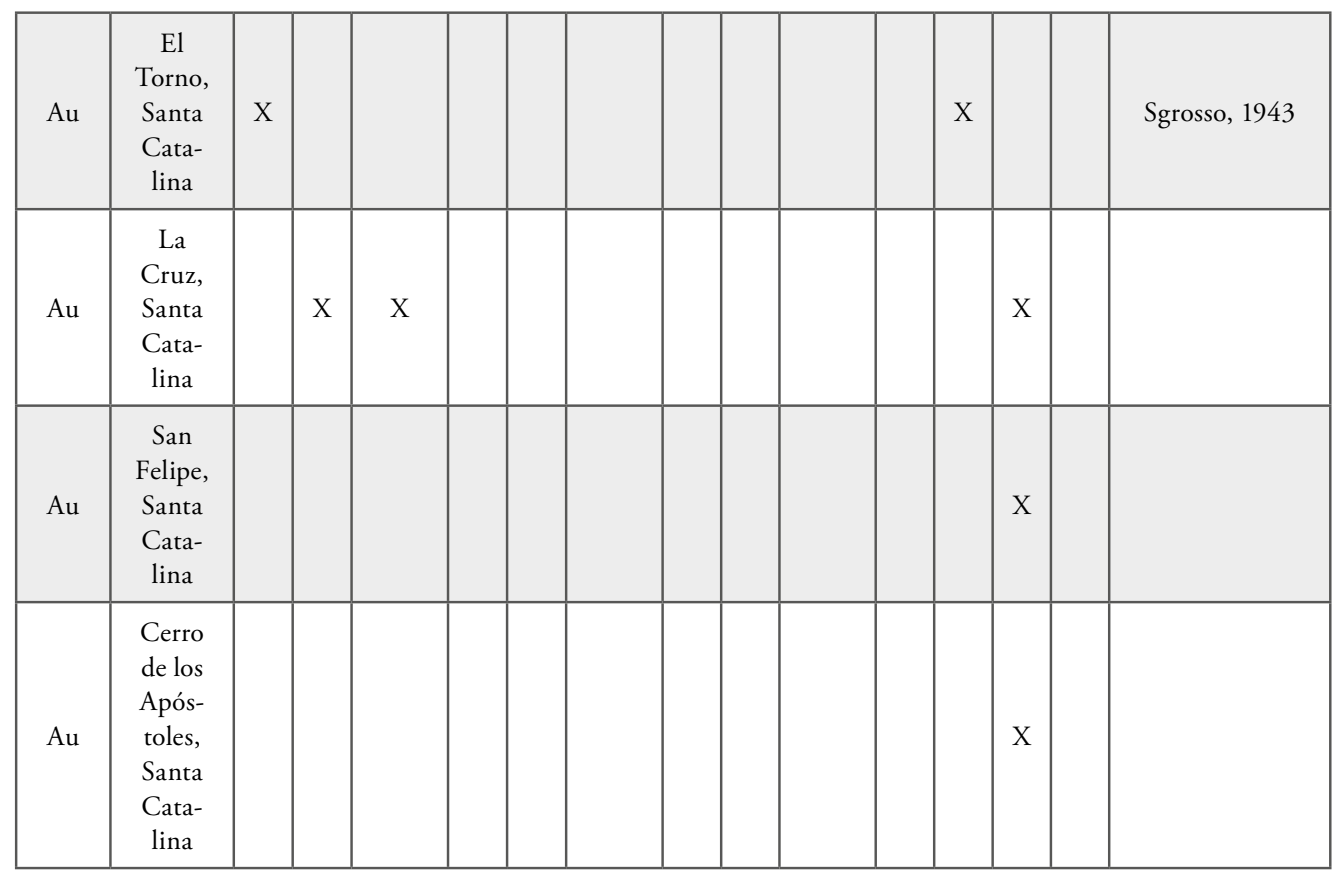

Con X se indica el tipo de evidencias antiguas presentes, si las mismas han sido registradas en documentación o investigaciones históricas (Registro histórico) (ver Becerra, 2014), en nuestros trabajos arqueológicos de campo (Registro arqueológico) (ver Angiorama y Becerra, 2010, 2012), y/o en bibliografía geológica donde hay menciones de labores antiguas. La explotación de algunos de ellos podría también remontarse a tiempos prehispánicos teniendo en cuenta su asociación espacial con ocupaciones precolombinas, tal como se indica en la columna de Evidencias prehispánicas.

* Este sitio ha sido registrado por Cruz (2010).

En el caso de las fuentes de minerales de cobre presentes en la cordillera Oriental, específicamente en la quebrada de Humahuaca, no se han hallado evidencias de explotaciones mineras que den cuenta de que en el lugar se hayan llevado a cabo tareas extractivas ni en momentos prehispánicos ni coloniales, a pesar de que, como detallaremos más adelante, las actividades metalúrgicas fueron habituales en los asentamientos prehispánicos de la quebrada (Angiorama, 2003). Debemos mencionar, no obstante, la presencia de evidencias indirectas de minería en contextos residenciales del asentamiento de Los Amarillos y en las casas-taller del Pukara de Tilcara, las cuales consisten en martillos líticos, mineral de cobre y, en el caso del último sitio, más de cuarenta astas de taruca (huemul) en los mismos recintos donde se recuperaron crisoles e intermediarios (Angiorama, 2003; Otero, 2013). Este instrumental sugiere que al menos algunos de los artesanos metalurgos de estos sitios podrían haber estado vinculados también a tareas de extracción minera. Debe señalarse, sin embargo, que las numerosas astas de taruca halladas en el Pukara de Tilcara podrían no haber sido empleadas en tareas mineras, tal como se ha propuesto para otros lugares (Boman, 1908; Angiorama, 2005b; Cruz, 2010), sino como mangos de artefactos metálicos o como pulidores e instrumental de grabado (Otero, 2013). La significativa ausencia de contextos de explotación minera en la quebrada y la presencia de ricos yacimientos minerales en el ambiente de puna han llevado a proponer que fueron estos la fuente de metal para la fabricación de los objetos producidos en los sitios quebradeños, ya sea en los de Humahuaca como en los de la vecina quebrada del Toro, en la actual provincia de Salta (Angiorama, 2003). 
El temprano conocimiento y explotación de minas de oro y de plata en el ambiente de puna por parte de los conquistadores espańoles, sumado a la numerosa población indígena que habitaba la región en tiempos prehispánicos tardíos, ha hecho pensar en la probabilidad de que esos mismos yacimientos hayan sido trabajados previamente (Angiorama, 2003, 2006; Angiorama y Becerra, 2010). En este sentido, Boman (1908) identificó una serie de minas posiblemente explotadas en momentos previos a la conquista europea, como por ejemplo parte de los numerosos pozos para extraer sedimento aurífero y lavaderos que rodean a la localidad de Rinconada. Décadas después, Raffino (1978) señaló expresamente la existencia de algunos asentamientos con evidencias de presencia inca vinculados a explotaciones mineras en la puna norte: El Moreno, Pukara de Rinconada, Sayate, Casabindo, Cochinoca y Puerta de Rinconada, un pequeńo asentamiento cercano a una veta aurífera. Sin embargo, en todos los casos no se trata más que del señalamiento de una relación espacial entre poblados y yacimientos minerales. En ninguno de los asentamientos mencionados hay hasta el momento evidencias claras de que sus habitantes se hayan dedicado a tareas minero-metalúrgicas de manera regular en tiempos prehispánicos. Una excepción podría ser Salviayoc, donde Raffino, Alvi, Olivera y Palma (1986, p. 74) registraron indicios de explotación aurífera -como escorias, canales y piletas circulares para el lavado de mineral- vinculados a arquitectura incaica. Este sitio, sin embargo, habría sido ocupado también intensamente durante los períodos colonial y republicano, lo que hace dudar de la cronología de las evidencias de actividad minero-metalúrgica detectadas.

Durante los últimos quince años, hemos realizado trabajos de campo en la puna de Jujuy especialmente diseñados para la identificación de minas prehispánicas (Angiorama y Becerra, 2010, 2012, 2014). Como resultado, hemos detectado numerosos yacimientos con evidencias asignables a momentos coloniales, pero solo algunos podrían tener una profundidad temporal mayor, sobre la base de una asociación espacial con ocupaciones prehispánicas, más o menos clara según cada caso (ver Tabla 1). Entre estos pocos yacimientos identificados se destaca el paraje rico en oro de Timón Cruz en la cuenca del río Santa Catalina, en el extremo noroccidental de la puna jujeña. Allí se localiza un asentamiento denominado Timón Cruz 2, el cual consiste en una concentración de estructuras de variada morfología, funcionalidad y cronología (Figura 2). Predominan los recintos habitacionales dispuestos en torno a patios, y grandes espacios de trabajo delimitados por muros bajos, en los que abundan percutores y yunques líticos asociados a fragmentos de cuarzo aurífero, lo que da cuenta del procesamiento de oro en el lugar. Si bien varias estructuras habitacionales de planta rectangular y con techo a dos aguas probablemente daten de los primeros momentos del período colonial (Angiorama, Becerra, Giusta y Pérez Pieroni, 2019), se observan otros tipos de recintos más antiguos, de tiempos prehispánicos. Un fechado obtenido en el piso de ocupación de uno de estos últimos, en el que se hallaron percutores similares a los distribuidos por la superficie del asentamiento, permitió datar su ocupación durante el siglo XIV de nuestra era. Se trata de la primera confirmación de la existencia de extracción y procesamiento de minerales de oro durante tiempos preincaicos en la puna de Jujuy. La cerámica de estilo yavi-chicha asociada a las herramientas mencionadas sugieren una explotación aurífera por parte de parcialidades chichas en Timón Cruz 2. Las excavaciones realizadas nos han permitido confirmar, además, que el asentamiento continuó ocupado durante el siglo XV DC, cuando el área ya había sido anexada al Tawantinsuyu. Esto permite suponer la continuación de las actividades mineras en el lugar durante tiempos incaicos, al igual que durante momentos coloniales tempranos. En las inmediaciones de este asentamiento se han observado desmontes, socavones, y una enorme superficie horadada por pozos y trincheras a lo largo de un curso de agua temporario. Asociadas a estas evidencias de actividad minera, hemos detectado algunas estructuras circulares que habrían funcionado como refugios. No obstante, no hemos encontrado en el lugar ni herramientas ni otro material que pudiera indicar 
la cronología de dichas explotaciones. La cercanía de las mismas a Timón Cruz 2 sugiere que los minerales procesados en este sitio provendrían de estas áreas con evidencias de extracción.

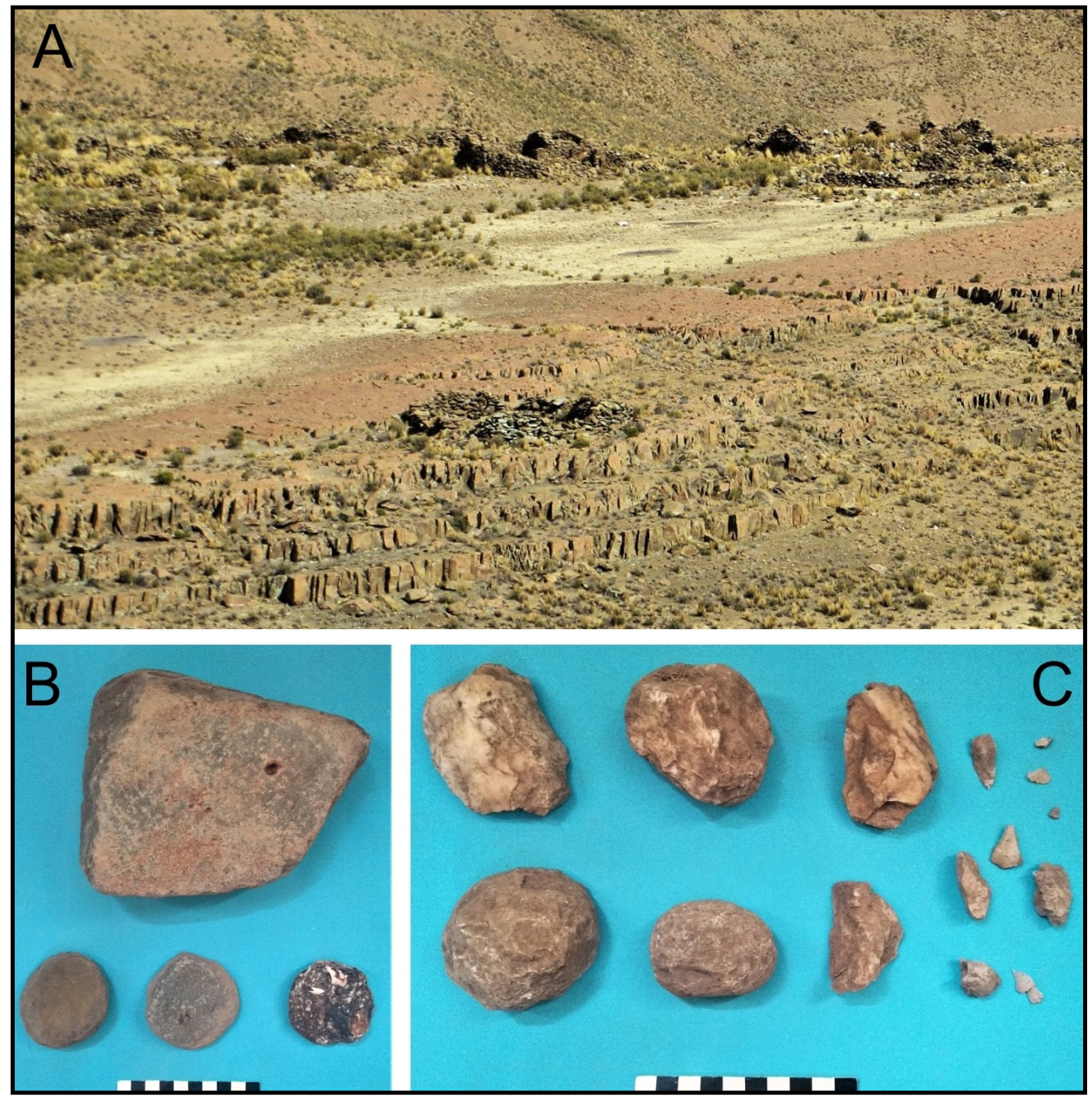

Figura 2. Timón Cruz 2.

a) Vista de parte del sitio; b) Yunque y percutores líticos;

c) Percutores líticos y fragmentos de cuarzo aurífero.

Por otra parte, en el valle de Coyahuayma, en los alrededores de la localidad actual de Rosario de Coyahuayma, se conservan numerosos pozos para la extracción de oro de filones y de depósitos aluviales, junto a estructuras residenciales probablemente vinculadas a esta actividad. Asimismo, en las cercanías de socavones más recientes se han hallado seis grandes instrumentos de molienda (marayes), y abundante mineral molido. Estos marayes presentan una morfología prehispánica, pero su uso continuó durante períodos posteriores. Sin embargo, resultan significativos el hallazgo de cerámica inca en este valle por parte del equipo dirigido por $\mathrm{H}$. Yacobaccio (com. pers.) y la existencia de un Recinto Perimetral Compuesto incaico junto a uno de los pozos de extracción más grandes de la zona. Todo esto nos permite suponer que la 
explotación del oro local se habría iniciado en momentos prehispánicos (Angiorama y Becerra, 2014) (Figura 3).

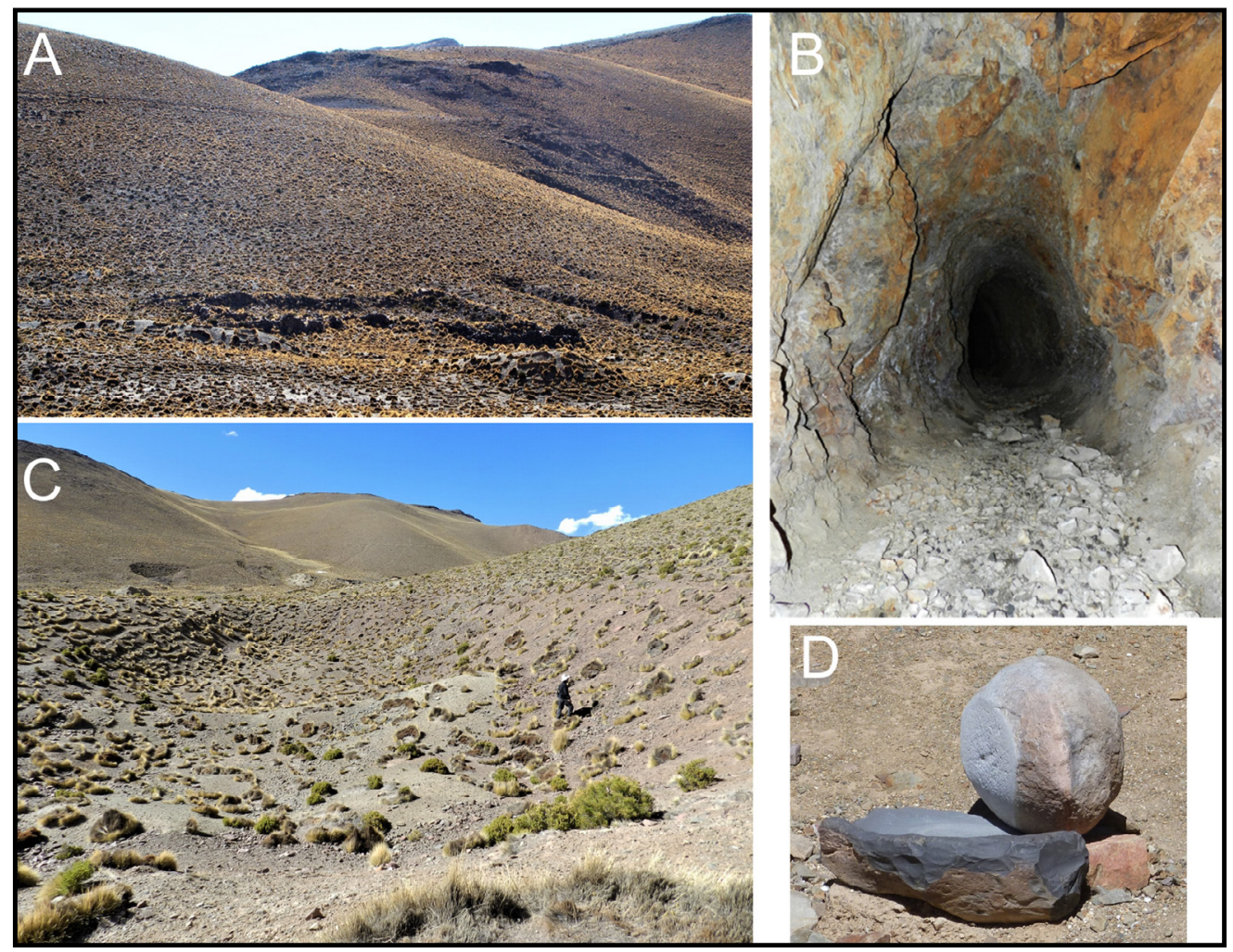

Figura 3. Rosario de Coyahuayma.

a) Construcciones incaicas; b) Socavón para la explotación de oro en veta;

c) Gran pozo para extracción de sedimento aurífero; d) Maray para molienda de mineral.

Otras evidencias posibles de minería precolombina, aunque menos claras que las anteriores, son las diversas áreas de lavado de mineral aurífero (trincheras y pozos) existentes en el sur de la cuenca de Pozuelos, asociadas a uno o dos recintos habitacionales de pequeńas dimensiones, probablemente empleados como refugios temporarios. Cinco de ellas, detectadas en el río San José, se encuentran en un área donde también se han registrado evidencias de ocupación prehispánica (Angiorama y Becerra, 2012, 2014). En la cuenca del río Santa Catalina, más al norte, se localizan varias áreas de explotación aurífera vinculadas a conjuntos habitacionales dispersos que datarían del período colonial (Angiorama y Becerra, 2012). Este es el caso de las estructuras habitacionales de planta rectangular con techo a dos aguas de Pueblo Viejo de Oratorio, asociadas a trincheras y pozos para el lavado de sedimento aurífero. No obstante, allí también hemos registrado evidencias de ocupación precolombina. Se trata de paneles con arte rupestre prehispánico tardío y un pequeño pukara (fortaleza) construido en la cima de un cerro que se eleva junto a la porción aurífera del río. No es claro aún, sin embargo, que la extracción de oro haya sido una de las actividades desarrolladas allí en aquel entonces (Angiorama y Becerra, 2014). 


\section{Actividades metalúrgicas prehispánicas}

En comparación con las actividades mineras, es mucho más lo que conocemos sobre las actividades metalúrgicas desarrolladas en momentos prehispánicos, especialmente para la cordillera Oriental y la puna. Para el caso de la ecorregión de las sierras subandinas y piedemonte, por el contrario, aún no se han encontrado evidencias que permitan asegurar que allí se desarrollaron tareas de producción metalúrgica, a pesar de que se han hallado algunos objetos metálicos (Ortiz, 2013).

Dentro de la ecorregión de la cordillera Oriental, la quebrada de Humahuaca ha sido considerada un centro metalúrgico prehispánico muy importante del NOA. Las evidencias de producción metalúrgica se encuentran en asentamientos de diversas características y funcionalidades (grandes, pequeños, complejos, simples, poblados, pukaras, de tiempos preincaicos, de momentos incaicos). Los contextos en los cuales estas evidencias fueron halladas también son variados (basureros, recintos domésticos, patios, espacios públicos, etc.). En aquellos casos en los que conocemos la cronología de las evidencias de producción, las mismas datan de tiempos preincaicos tardíos e incaicos. Es decir, no hay evidencias hasta el momento que se remonten al primer milenio de nuestra era o anteriores.

Los hallazgos más frecuentes consisten en fragmentos de escorias metalúrgicas, de residuos de fundición, y de refractarios que cumplieron la función de moldes o crisoles (por ejemplo, en Ciénega Grande -Salas, 1945-; Juella -Cigliano, 1967-; Puerta de Juella-Mayer, 1986-; Pueblo Viejo de la Cueva -Basílico, 1992-). De entre todos los contextos en los que fueron encontrados, se destacan los tres siguientes por constituir lugares en los que efectivamente se han desarrollado tareas vinculadas con alguna de las etapas de la producción metalúrgica, y por haber sido estudiados con mayor profundidad.

Uno de ellos es un conjunto arquitectónico localizado en el Pukara de Tilcara (Unidad Habitacional 1), ocupado entre los siglos XI y XIII de nuestra era, compuesto por varios recintos intercomunicados. Mientras que uno de ellos habría sido utilizado como albergue o habitación, en los restantes se hallaron evidencias vinculadas con una amplia variedad de actividades, tales como cocción y consumo de alimentos, modelado y decoración de alfarería, molienda de pigmentos minerales, preparación de pasta de arcilla para la producción de alfarería, y fabricación de objetos metálicos (Tarragó, 1992; Tarragó y González, 1998). Las evidencias arqueometalúrgicas consisten en estructuras de combustión del tipo fogón de gran tamaño, restos de minerales metalíferos, escorias, refractarios, residuos de fundición, instrumental lítico y objetos metálicos. Tomando como base los hallazgos realizados, se propuso que en la estructura se llevaron a cabo actividades metalúrgicas orientadas a la refinación de metales, a la materialización de aleaciones y a los distintos pasos seguidos en la manufactura de objetos metálicos, como el vaciado en moldes y templado (Tarragó y González, 1998; Otero y Tarragó, 2017). A pesar de que los fragmentos de moldes indican que allí se habrían colado fundamentalmente bienes "ornamentales" (como grandes discos circulares similares a los hallados en otros contextos del Pukara de Tilcara), en el lugar solo se recuperaron objetos metálicos con función "utilitaria". Para dichos investigadores, la producción metalúrgica habría estado destinada entonces a un consumo externo, fuera de la unidad residente, y habrían existido "instancias políticas superiores al grupo, que controlaban, directa o indirectamente, las fuentes de materias primas, la capacidad laborativa de los operarios y la distribución social de los bienes producidos" (Tarragó y González, 1998, p. 192). La producción y el uso de objetos metálicos, entonces, se habrían 
desarrollado en función de los intereses de los líderes locales, y bajo su control. Luego, en el marco de las estrategias incas, este espacio habría sido transformado para montar una unidad productiva especializada del tipo multiartesanal, aprovechando los saberes y la estructura preexistente (Otero y Tarragó, 2017). Este taller no habría sido el único, sino uno más de las numerosas casas-taller con muy amplia dispersión dentro del pukara, dedicadas a la producción especializada de bienes artesanales para el Inka, tanto de lapidaria como metalúrgica. Analizando piezas de colección, libretas de campo y a partir de sus propias excavaciones en el sitio, Otero (2013) ha logrado identificar más de cincuenta estructuras que en distintos sectores del pukara presentan evidencias de producción lapidaria y metalúrgica. Las residencias de los funcionarios que habrían controlado dichas tareas especializadas se habrían encontrado dispersas entre las distintas casas-taller. Sobre esta base, Otero y Tarragó (2017) señalan que a diferencia de la producción lapidaria, que funcionó exclusivamente para la demanda extrarregional, la metalurgia habría tenido como objetivo la producción de bienes ornamentales y altamente simbólicos de consumo en el pukara y en el ámbito regional, pero también de instrumental destinado a otras actividades productivas dentro del mismo asentamiento.

Por otra parte, las excavaciones en una vivienda doméstica (Unidad 400) del sitio Los Amarillos hicieron posible el hallazgo de un conjunto de evidencias arqueometalúrgicas que permiten postular que allí tuvieron lugar ciertas actividades vinculadas con la producción de objetos metálicos durante tiempos preincaicos tardíos (1280-1430 DC) (Angiorama, 2005b) (Figura 4). La vivienda se localiza en uno de los sectores habitacionales periféricos del asentamiento. Diversos análisis realizados sobre las evidencias registradas en ella permitieron identificar referentes materiales de una amplia gama de actividades vinculadas al quehacer del grupo doméstico que la habitaba y que abarcaba tareas relacionadas con diferentes etapas del proceso productivo, desde la obtención hasta el descarte de variadas materias primas y artefactos. Se hallaron elementos que indicaban que en el lugar se llevaron a cabo tareas de preparación, consumo y almacenaje de alimentos, talla de instrumentos líticos, uso y depósito de objetos domésticos variados, actividades rituales de carácter doméstico, remodelaciones arquitectónicas y funcionales acordes a la evolución del grupo corresidente, entre otras (Taboada, 2005, 2010). Los hallazgos relacionados con la producción metalúrgica sugieren, en primer lugar, que allí se habrían terminado de elaborar objetos metálicos mediante martillado y pulido. En la estructura excavada se han encontrado dos preformas de metal, cinceles a los cuales les falta conformar el filo, y un fragmento de cuchillo rectangular cuyo filo fue reactivado. Estos elementos han sido hallados asociados a instrumentos que parecen haber sido empleados para el martillado de objetos metálicos, precisamente la técnica apropiada para culminar la fabricación de las piezas mencionadas. Las herramientas en cuestión son martillos y yunques líticos de formas y tamańos muy variados, algunas rocas con rastros de haber sido utilizadas como pulidores, y una piedra plana de gran tamańo apoyada sobre el piso del recinto, con numerosas estrías, marcas de percusión y sectores con intenso pulido. La variedad de formas y tamaños de los martillos encontrados indica que en la estructura se habrían llevado a cabo tanto percusiones que requerían imprimir fuerza como golpes más sutiles, en los cuales era más importante la precisión (Angiorama, 2005b). Esto sugiere que, si todos fueron empleados para el trabajo del metal, algunos estuvieron destinados a tareas tales como dar forma y endurecer filos de instrumentos cortantes, y otros al laminado de piezas delicadas o al retoque de objetos pequeños. Dos de los yunques recuperados en este contexto conservan una fina capa de óxido de cobre adherida, producto del martillado de objetos metálicos sobre ellos. Estos fueron encontrados asociados a dos fogones de la vivienda, probablemente dedicados a los eventos sucesivos de martillado y recocido de artefactos de metal. 

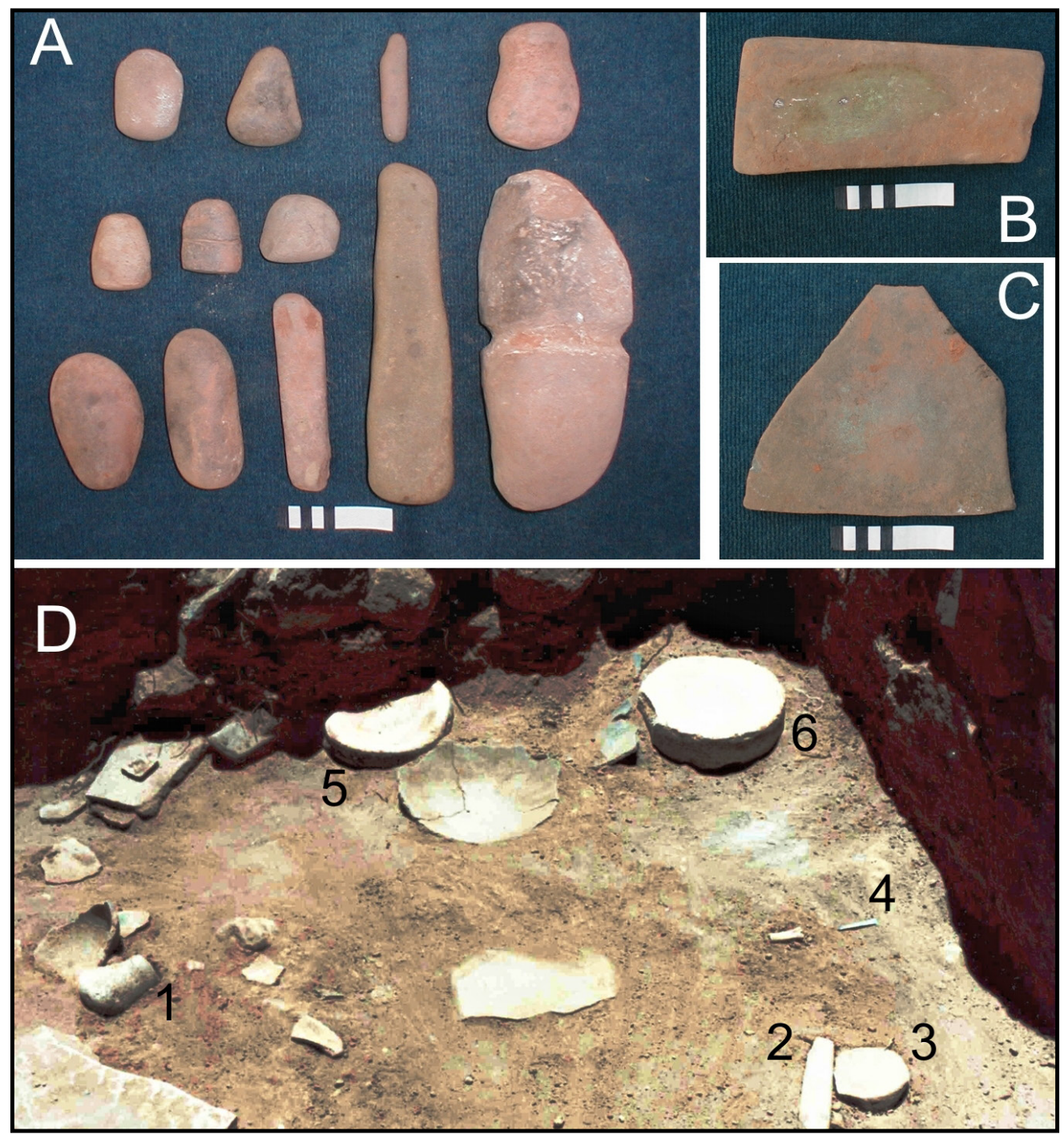

Figura 4. Hallazgos preincaicos en la Unidad 400 de Los Amarillos.

a) Martillos líticos; b y c) Yunques líticos con cobre adherido; d) Parte del contexto de hallazgo: 1 y 2) Martillos líticos; 3) Yunque lítico; 4) Preforma de cincel de metal; 5 y 6) Recipientes líticos probablemente vinculados con producción metalúrgica (ver Angiorama, 2005b).

Aparentemente, dentro de esa vivienda de Los Amarillos no se realizaron otros tipos de tareas metalúrgicas, tales como fundiciones o vaciado de objetos. Parece ser que el metal llegaba listo para ser trabajado directamente por martillado, ya sea como preforma, gota de fundición o artefacto para ser reparado. Sin embargo, no se puede asegurar que no hayan sido las mismas personas las que realizaban, en otros lugares, las etapas previas del proceso. Ya mencionamos el hallazgo en la estructura de algunos elementos indicadores de actividades mineras, como martillos de gran porte y mineral de cobre. Estas evidencias sugieren que quizás los mismos habitantes participaban en la explotación de yacimientos minerales (Angiorama, 2005b).

Durante el período Incaico, en el sector central de Los Amarillos se llevaron a cabo también ciertas actividades de producción metalúrgica (Angiorama, 2003, 2005a) (Figura 5). La superposición de 
capas de fosfato de calcio en un crisol y en los moldes hallados, y la estratigrafía de la estructura de combustión utilizada con fines metalúrgicos, indican que no se llevó a cabo un único evento de fundición y colada sino que el proceso se repitió varias veces. Estas evidencias sugieren que los operarios locales recibían el metal luego de haber sido obtenido por reducción de sus menas en otro lugar, y probablemente ya sometido a un proceso de refinación, y allí los metalurgos lo refundían, posiblemente elaboraban aleaciones, y lo colaban en moldes para obtener ciertos tipos de objetos. De los cuatro que se han podido identificar, dos son piezas típicamente incaicas en el NOA (un topu y un tumi), y los dos restantes consisten en posibles lingotes de formas diferentes. Se procesaron diversas combinaciones de cobre, estańo y oro, evidenciadas por las gotas de fundición y los recortes metálicos analizados (Angiorama 2001, 2003). La producción habría estado destinada fundamentalmente a ser transportada fuera de Los Amarillos, quizás para ser empleada como tributo al Estado (Angiorama, 2005a, 2011b).

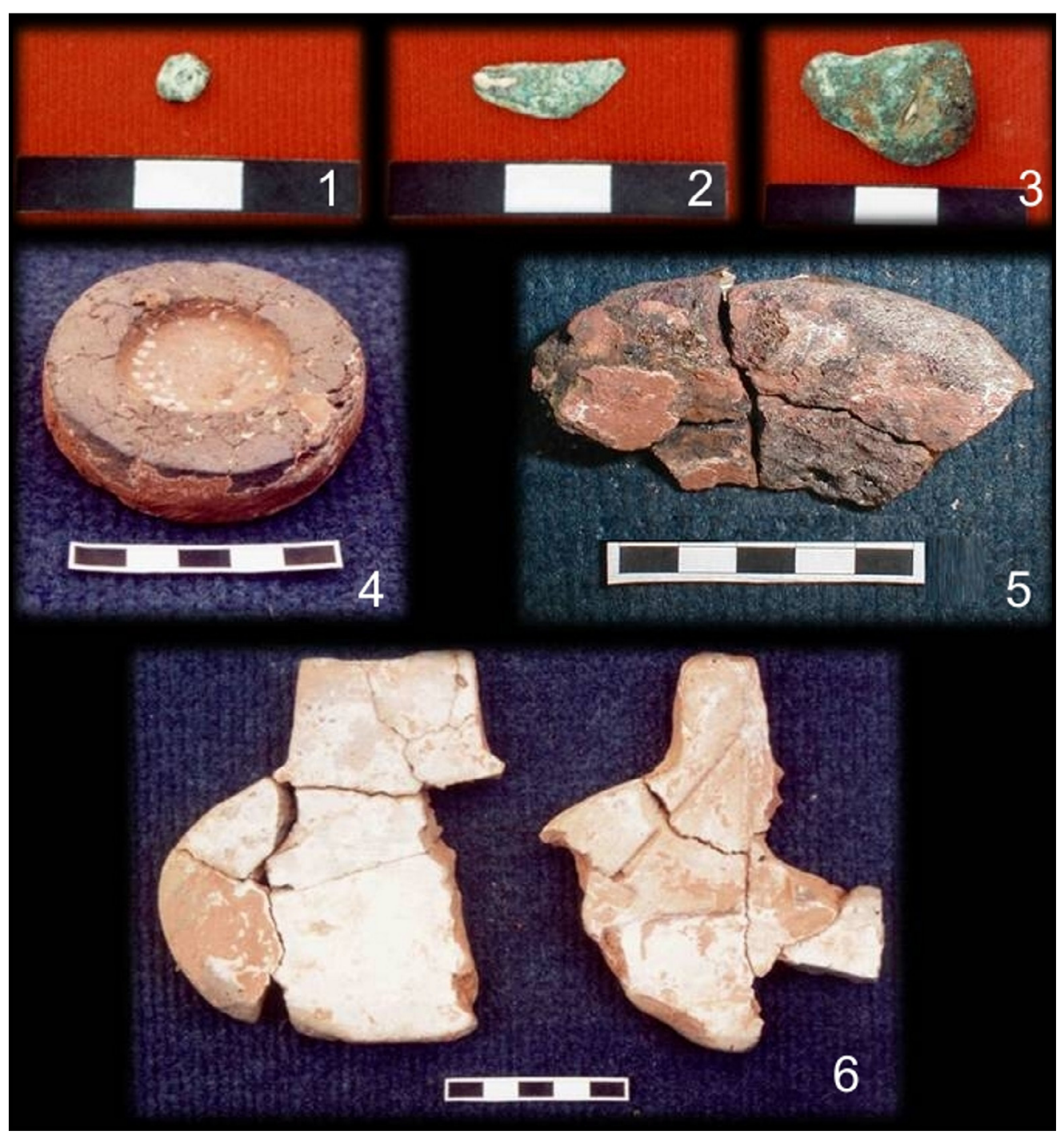

Figura 5. Hallazgos vinculados a tareas de producción metalúrgica encontrados en contextos de época incaica en Los Amarillos.1) Gota; 2) Recorte de metal; 3) Tejuela; 4) Molde metalúrgico;

5) Fragmento de crisol; 6) Molde metalúrgico bivalvo para la obtención simultánea de un topu y un tumi. 
Las investigaciones arqueológicas llevadas a cabo en la puna han permitido el registro de unas pocas evidencias de actividades metalúrgicas desarrolladas en la región durante tiempos prehispánicos. Lamentablemente, a diferencia de los contextos productivos que se han podido identificar en la quebrada de Humahuaca, estas evidencias son por lo general hallazgos aislados, que remiten a la actividad pero que se encontraron en contextos no productivos, en superficie, o desconocidos (por ser piezas de colecciones de museos conformadas en la primera mitad del siglo XX). Ejemplos de estos son tejuelas, fragmentos metálicos y posibles lingotes de cobre y bronce estañífero, que podrían haber sido reservorios de metal para ser refundidos para la fabricación de objetos, hallados en Queta, Finispatriae, Pukara de Rinconada, Pueblo Viejo de Tucute/Sorcuyo, Ojo de Agua y Casabindo (Von Rosen, 1919/1957; Zaburlín, 2014; Nielsen, Angiorama, Maryañski, Ávila y López, 2015; Becerra, Angiorama y Plaza, 2020). También se han reportado escorias metalúrgicas y escasos fragmentos de moldes y crisoles, confeccionados en material refractario en Doncellas, Sansana y Finispatriae (Krapovickas y Aleksandrowicz, 1986-1987; Zaburlín, 2014; Nielsen et al., 2015). En dos grandes

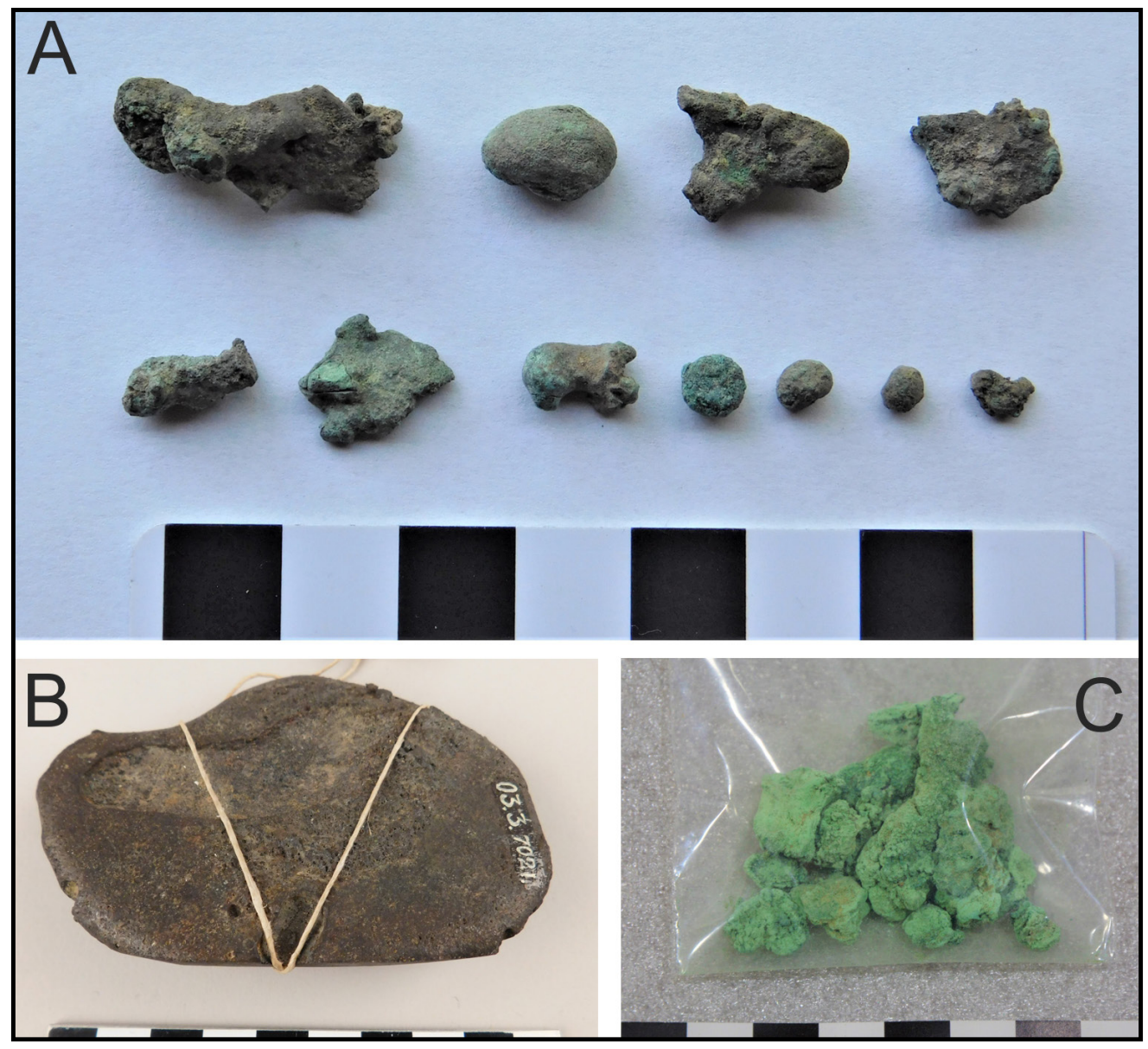

Figura 6. Evidencias de posibles actividades metalúrgicas realizadas en sitios de la puna.

a) Residuos de fundición hallados en Moreta; b) Reservorio de metal o lingote encontrado en Casabindo por Von Rosen (1919/1957). 1903.03.7021. Colección Von Rosen, Museo Etnográfico, Museos de la Cultura Mundial, Estocolmo, Suecia; c) Lote de óxido de cobre hallado en Doncellas por Eduardo Casanova. Inventario No42-836, Colección Exc. Casanova, Eduardo 1942 (Donación MACN 1947), Museo Etnográfico J. B. Ambrosetti, Facultad de Filosofía y Letras, Universidad de Buenos Aires, Argentina. 
asentamientos de esta ecorregión, sin embargo, estos hallazgos han sido un poco más abundantes: Doncellas y Moreta (Figura 6). Exceptuando los casos para los cuales no se conoce la antigüedad de los hallazgos, por haber sido encontrados en superficie, los restantes se tratan de elementos prehispánicos tardíos o incaicos (siglos XI a XVI DC). Es decir, no hay hasta ahora tampoco en la puna evidencias de actividades metalúrgicas llevadas adelante durante el primer milenio de nuestra era, o antes.

En Doncellas, asentamiento ocupado al menos desde el siglo VIII al XVII DC, se recuperaron poco más de 10 trozos metálicos de cobre fundido, sumados a algunas láminas y fragmentos de objetos del mismo metal, quizás reservorios destinados a ser procesados. A ellos se agregan tres trozos de escoria de cobre, un fragmento de una posible tobera para avivar el fuego durante la fundición, y un fragmento de un molde para la confección de dos tumis (Alfaro de Lanzone, 1988; Pérez, 2006-2007; Zaburlín, 2014). Sin embargo, los trabajos de campo realizados en el sitio hasta el momento no han dado como resultado el hallazgo de algún contexto en el cual hayan tenido lugar actividades relacionadas con la producción metalúrgica.

En Moreta, asentamiento habitado al menos desde el siglo VII hasta el XVI DC, se han hallado 17 tejuelas y gotas de fundición, indicadoras de posibles prácticas metalúrgicas en el lugar. Todos los residuos de fundición, con excepción de uno, han sido hallados en superficie, por lo que se desconoce su cronología. La pieza restante fue hallada en un contexto fechado en los siglos XII y XIII de nuestra era, es decir, en tiempos preincaicos (Angiorama, Pérez Pieroni y Becerra, 2017). Es interesante que 11 de los residuos de fundición (tanto tejuelas como gotas) han sido encontrados concentrados en un pequeño sector de menos de $2 \mathrm{~m}$ de diámetro, donde se observan evidencias de termoalteración en la superficie, lugar donde posiblemente se desarrollaron actividades metalúrgicas. Se ha analizado la composición de 14 de los residuos de fundición: 13 consisten en aleaciones de bronce estañífero, mientras que el restante es de cobre con algunas impurezas. Los análisis sugieren que podrían ser el resultado de la producción de aleaciones en el lugar, mezclas intencionales de estańo por un lado y cobre rico en azufre por otro. El mineral procesado para las muestras con azufre pudo ser calcopirita, que se encuentra presente en casi todos los yacimientos de cobre de la región (Angiorama et al., 2017).

A los hallazgos mencionados podemos sumar los realizados en otros tres sitios arqueológicos del sur de la cuenca de Pozuelos ocupados en tiempos prehispánicos: Chajarahuaico 25, Pan de Azúcar, y Tabladitas 1. De acuerdo con evidencias encontradas en superficie, en ellos se llevó a cabo la fundición de sulfuros de plomo y plata. Allí se han registrado los cimientos de hornos con rocas termoalteradas y fragmentos de minerales y escoria metalúrgica en sus cercanías (Angiorama y Becerra, 2010). La dificultad para datar las evidencias de los dos primeros sitios radica en que en ambos se han hallado tanto indicadores de ocupación prehispánica como colonial. Tabladitas 1, en cambio, parece haber sido un caserío ocupado únicamente en tiempos prehispánicos. Sin embargo, el hecho de que las evidencias de producción metalúrgica hayan sido encontradas en superficie no permite asegurar su cronología (Angiorama y Becerra, 2014).

\section{Discusión}

Siguiendo un eje cronológico, las investigaciones arqueológicas llevadas a cabo hasta el momento en la provincia de Jujuy nos muestran que para tiempos preincaicos (hasta el $1430 \mathrm{DC}$ aprox.), las evidencias de actividades mineras son pocas y se localizan fundamentalmente en la puna. Ante esta escasez de información, a pesar de la riqueza en fuentes minerales de la región, ya hemos mencionado la posibilidad de que las intensas actividades mineras llevadas a cabo 
durante tiempos coloniales y republicanos hayan destruido las evidencias más antiguas. La minería, en cualquiera de sus formas, es una actividad que altera inevitablemente el terreno en el que se la practica, dificultando la preservación de restos arqueológicos preexistentes. También es posible que haya existido casi exclusivamente una explotación a baja escala, de manera temporaria, como en el cauce de ciertos ríos de la puna, sin dejar mayores evidencias datables de las prácticas de lavado de oro o extracción de veta. Sin embargo, las tareas mineras no parecen haber sido intensas en tiempos preincaicos. El único lugar donde se ha podido confirmar fehacientemente la explotación de oro antes de la incorporación del NOA al Tawantinsuyu es en Timón Cruz 2. Las evidencias sugieren que habrían sido trabajadores chichas los que desarrollaron tales actividades, lo que resulta interesante considerando la relativa alta frecuencia en la región de la presencia de objetos de oro en tumbas con cerámica adscribible al estilo yavichicha. Esto contrasta con la escasez de objetos de ese metal en tumbas localizadas más al sur de los límites del área chicha (por ejemplo, Boman, 1908; von Rosen 1919/1957).

Los indicadores de producción metalúrgica durante tiempos preincaicos son inexistentes hasta ahora en la ecorregión de sierras subandinas y piedemonte, y escasos en la puna, donde indican fundamentalmente el procesamiento de cobre y bronce estañífero. Las características de los residuos metálicos hallados en Moreta resultan en todo concordantes con las típicas de tiempos prehispánicos para el NOA. Aunque es cierto que no han sido hallados asociados a otras evidencias de producción metalúrgica (tales como crisoles, moldes, etc.), su presencia sugiere que en el sitio efectivamente pudieron haber tenido lugar tales actividades, ya que es poco probable que el bronce haya circulado por las redes de tráfico de tiempos preincaicos e incaicos como objetos de ese tipo y tamańo. Con frecuencia este tipo de piezas son el resultado de extravíos de metal producidos en el momento de la fundición en crisoles o del vaciado en moldes (González, 2004; Angiorama, 2005a).

En la quebrada de Humahuaca, por el contrario, las evidencias de producción metalúrgica son abundantes, con la implementación de técnicas variadas y la manipulación de aleaciones diversas. El acceso al estańo, posiblemente procedente de la puna, no parece haber estado restringido a algún sector de la población en particular. La producción de objetos pudo haber sido controlada en el contexto estudiado del Pukara de Tilcara (Tarragó y González, 1998), pero no en otros asentamientos de la región, donde si se ejerció algún tipo de control, probablemente este se centró exclusivamente en la fabricación de ciertos objetos que por algún motivo revestían una importancia especial, tales como grandes discos o campanas (Angiorama, 2005b). Las investigaciones efectuadas en Los Amarillos indican que en ese ámbito doméstico, en el cual el grupo que lo habitaba llevó a cabo tanto tareas de subsistencia como artesanales, no se observan elementos que permitan postular que la producción de objetos metálicos se haya llevado a cabo bajo un control externo. Las actividades metalúrgicas parecen haber constituido una más de una gran variedad de tareas que se desarrollaban en el lugar e, incluso, los mismos residentes habrían podido estar involucrados en la explotación de los yacimientos minerales.

De la misma manera, parece ser que tampoco existió en la quebrada de Humahuaca una restricción en el uso de objetos metálicos durante tiempos preincaicos. Tanto los artefactos de cobre como de bronce, los más abundantes en la región, han sido encontrados en una enorme variedad de sitios y contextos (Angiorama, 2003).

En tiempos incaicos (1430-1535 DC) la explotación minera parece haber sido mucho menos extensiva e intensiva de lo que se había propuesto (Raffino, 1978; González, 1983, entre otros). De hecho, hasta el momento no hay registro de una vinculación directa entre los 
asentamientos imperiales o anexados al incario en la puna (tales como Calahoyo, Moreta y Pukara de Rinconada) y las áreas mineras detectadas por nosotros. El ramal del Qhapaq Nam que atraviesa el área y los tambos instalados a su vera se encuentran emplazados alejados de los yacimientos de oro y plata de la Sierra de Rinconada (Angiorama, 2011a), enmarcados en un paisaje prehispánico con una clara orientación pastoril y, en ciertos sectores, como Carahuasi, agrícola. Por otra parte, no se han registrado santuarios de altura o centros ceremoniales vinculados a los cerros minerales, tal como se han identificado en otras áreas donde el Inka tuvo intereses mineros concretos (Cruz, 2009). El único hallazgo que podría estar vinculado con una apropiación simbólica de una fuente de mineral, aunque no metalífero, es el sacrificio de un niño en las inmediaciones de las Salinas Grandes (Boman, 1918; Besom, 2010), lo que daría cuenta de la relevancia de este recurso para el Tawantinsuyu, aunque desconocemos las características o mecanismos implementados para su explotación durante su dominio.

Siempre teniendo en cuenta que las explotaciones mineras coloniales y republicanas pueden haber ocultado o destruido los indicadores de minería más antigua, hasta el momento podemos identificar trabajos de extracción durante tiempos incaicos únicamente en tres lugares de la provincia de Jujuy: cobre en el cerro Fundición, en las sierras subandinas (Cruz, 2010), y oro en Timón Cruz 2 y en Rosario de Coyahuayma, en la puna. Si bien las investigaciones en estos últimos dos lugares están recién en sus inicios, resulta interesante remarcar que parecen tratarse de dos tipos de explotaciones diferentes. En Timón Cruz 2, por una parte, observamos una continuidad de las explotaciones previas, sin grandes cambios identificables por ahora. Quizás se trata simplemente de la perduración de las actividades extractivas cuando ya la región había sido anexada al Imperio. La presencia de cerámica incaica en el asentamiento (Pérez Pieroni, 2015) demuestra que las redes de circulación de bienes imperiales ya estaban operando en el área, pero la ausencia de una arquitectura con rasgos incaicos nos impiden asegurar la presencia en el lugar de funcionarios o trabajadores estatales. En Coyahuayma, por otra parte, la existencia de un Recinto Perimetral Compuesto (RPC) incaico junto a los pozos y trincheras mineras más grandes del valle indica claramente la presencia del Estado en el lugar como auspiciante de la explotación aurífera.

Aún es poco lo que sabemos acerca de las características que habrían adquirido tanto el proceso de producción metalúrgica como la circulación de los objetos fabricados en la quebrada de Humahuaca durante la época incaica. En general, las evidencias nos indican la ocurrencia en el NOA de importantes transformaciones en la organización de la producción metalúrgica en tiempos del Tawantinsuyu, acompańadas por un gran aumento en la escala productiva. Al amplio repertorio local de objetos se agregaron nuevos tipos, como ciertas clases de topus $y$ tumis, liwis, hachas con forma de ancla y mazas estrelladas (González, 2004). Sin embargo, aparentemente los incas no habrían introducido innovaciones tecnológicas significativas, sino que, por el contrario, adoptaron algunas soluciones técnicas locales para la confección de las piezas metálicas, como la práctica de recubrir los crisoles y moldes con fosfato de calcio para evitar el anclaje del metal fundido a las paredes de los refractarios, y el uso de las denominadas cucharas o intermediarios para la dosificación del metal líquido en los moldes (González, $1997,2004)$. Incluso se ha planteado que algunas de estas prácticas habrían sido luego implementadas por el Imperio en otros lugares del Tawantinsuyu, como por ejemplo en el norte de Chile (González, 2004).

Las evidencias de producción metalúrgica durante tiempos incaicos son escasas en Jujuy. No se han hallado hasta el momento en ninguna de las tres ecorregiones indicios de una metalurgia a gran escala como los encontrados en otros lugares del NOA, como Rincón Chico (González, 
2004) o Quillay (Spina et al., 2017), en la provincia de Catamarca. Por el contrario, las únicas evidencias claras son las del sector central de Los Amarillos y al menos una de las casas-taller del Pukara de Tilcara (Otero, 2013). Estas indican la manipulación de cobre, estańo, plata y oro, lo que implica que, tal como ocurría en tiempos preincaicos, la variedad de yacimientos explotados siguió siendo grande, y que las rutas de tráfico de minerales siguieron siendo diversas. Es posible que la producción de piezas metálicas haya sido desempeñada por operarios locales, a juzgar por ciertas soluciones tecnológicas empleadas. La ausencia de objetos metálicos terminados en el componente incaico del sector central de Los Amarillos parece indicar que las piezas que allí se confeccionaban, aparentemente a baja escala, eran elaboradas para ser luego transportadas hacia otros lugares, acaso para ser empleadas como tributo (Angiorama, 2005a, 2011b). La movilización de productos en esta forma en la quebrada de Humahuaca durante la época incaica ha sido señalada ya por varios autores, e incluyó tanto bienes básicos (como los agrícolas) como manufacturados (Nielsen, 1998). Por testimonio de los primeros conquistadores, sabemos que el transporte de metales durante tiempos incaicos era una práctica regular, apoyada por una compleja organización. Es probable que durante la anexión del territorio al Tawantinsuyu la producción metalúrgica haya continuado en gran parte de la quebrada de Humahuaca sin el auspicio directo del Estado. El Pukara de Tilcara sería una excepción, con la presencia de funcionarios enviados por el Inka para el control de las actividades productivas (Otero, 2013; Otero y Tarragó, 2017).

\section{Consideraciones finales}

A lo largo de este trabajo hemos detallado las diferentes evidencias de actividades mineras y metalúrgicas que han sido registradas hasta ahora en las tres ecorregiones de lo que actualmente es el territorio de la provincia de Jujuy. Como adelantamos, la cordillera Oriental, especialmente la quebrada de Humahuaca, ha sido foco de la mayoría de los trabajos arqueológicos en la provincia, pero, por otra parte, ha sido en la puna donde se han realizado prospecciones sistemáticas diseñadas específicamente para la identificación de evidencias directas de actividad minera asignables a momentos prehispánicos (Angiorama y Becerra, 2010, 2014). En el caso de las sierras subandinas, solo en el sector de Calilegua se han llevado adelante estudios de estas características (Cruz, 2010).

Aunque aún estamos lejos de conocer acabadamente el desarrollo de las prácticas minero-metalúrgicas en este territorio, esta revisión nos permite arribar a una serie de consideraciones sobre las mismas. A pesar de la riqueza mineral de la ecorregión puneña, las actividades mineras tanto en momentos preincaicos como incaicos no parecen haber adquirido una gran escala, ni en extensión ni en intensidad. No descartamos que las explotaciones coloniales y republicanas en el área hayan borrado algunas de las evidencias de extracción minera previas, pero más allá de ello, no se observa una organización del espacio puneńo especialmente orientado a una actividad extractiva a nivel imperial tal como se ha detectado en otras regiones del Tawantinsuyu (Salazar et al., 2013). Por otra parte, la mayoría de las labores mineras identificadas como posiblemente prehispánicas presentan indicadores insuficientes para una asignación cronológica segura, ya que la misma se basa en su vinculación espacial con otras evidencias prehispánicas sin certeza "de los procesos que pudieron conducir a su asociación superficial con desmontes o explotaciones mineras" (Salazar y Vilches, 2014, p. 8). Es notable, asimismo, la ausencia en contextos extractivos de herramientas líticas u otras evidencias in situ indiscutiblemente prehispánicas, que permitan confirmar la explotación de minerales metalíferos para ese período, tales como las hachas y martillos líticos para la extracción y procesamiento de sal encontrados 
en Salinas Grandes por la Expedición Sueca y la Misión Francesa de principios del siglo XX (Nordenskiöld, 1903; Boman, 1908). Los instrumentos de molienda registrados en el valle de Coyahuayma podrían ser asignables a momentos prehispánicos, pero la continuación de la explotación de ese yacimiento y del empleo de ese tipo de herramientas en tiempos posteriores impide una asignación cronológica segura. No es el caso de los percutores hallados en un recinto habitacional de Timón Cruz 2, en niveles de ocupación con fechado radiocarbónico, pero no se trataría de un contexto minero propiamente tal. De hecho, en todo el NOA, solo se conocen dos sitios mineros en los que se han hallado martillos líticos vinculados directamente a la extracción de minerales de cobre. Uno de ellos es el mineral de Capillitas, en la provincia de Catamarca, donde Lafone Quevedo menciona "combos de piedra hallados en las labores primitivas" (Lafone Quevedo, 1894/2010, p. 132). El otro es la Cueva Inca Viejo en la puna salteña, donde López, Coloca, Rosenbusch y Solá (2018) han identificado martillos dedicados a la extracción de minerales de cobre para lapidaria.

Las evidencias de actividades metalúrgicas son comparativamente más abundantes y permiten conocer un poco más sobre su desarrollo y sobre los cambios producidos con la conquista del Imperio, aunque esto únicamente para el caso de los contextos de la quebrada de Humahuaca. Como mencionamos, las evidencias registradas en la región puneña son indicativas del manejo de cobre y sus aleaciones en tiempos prehispánicos, pero se trata más bien de hallazgos descontextualizados o no asociados a contextos productivos claros. Los estudios realizados en dos sectores de Los Amarillos nos muestran, por un lado, cómo la organización de la producción y el uso de objetos metálicos durante época preincaica tardía habría sido más variada de lo asumido hasta el momento, sin un uso restringido de las piezas metálicas para la jerarquía local ni un control externo (Angiorama, 2005b), como sí habría ocurrido quizás en el Pukara de Tilcara (Tarragó y González, 1998). Para momentos incaicos, las evidencias indicarían, como en otros centros metalúrgicos del NOA, modificaciones en la organización y acceso a las fuentes de materia prima y distribución de los objetos (Angiorama, 2011b). Esto no habría impedido, sin embargo, que ciertas prácticas metalúrgicas o de empleo de bienes metálicos continuaran por fuera de la órbita imperial, escapando del control del Inka, tal como se ha registrado en otras áreas del Tawantinsuyu, tanto en el caso de actividades mineras (Garrido, 2017) como metalúrgicas (Zagorodny, Angiorama, Becerra y Pérez Pieroni, 2015).

Las numerosas investigaciones arqueológicas en curso en la provincia de Jujuy permitirán poco a poco ir completando el panorama aquí esbozado, generando nueva información sobre dos de las actividades productivas más complejas de las desarrolladas en el NOA durante tiempos prehispánicos: la explotación de minerales metalíferos y la fabricación de objetos metálicos.

\section{Agradecimientos}

Los trabajos de campo y laboratorio han sido posibles gracias al financiamiento del Consejo Nacional de Investigaciones Científicas y Técnicas (CONICET, Argentina), Proyecto PIP 2015-0055, del Fondo para la Investigación Científica y Tecnológica (FONCYT, Argentina), Proyectos PICT 2014-2085 y PICT 2017-0732, de la Secretaría de Ciencia y Técnica de la Universidad Nacional de Tucumán (CIUNT, Argentina), Proyecto PIUNT 2018-G604, y del Programa de Movilidad Docente UBAINT de la Universidad de Buenos Aires. Agradecemos especialmente a los pobladores de la puna por permitirnos desde hace dos décadas realizar nuestras investigaciones en la región, y a todo el equipo del Grupo de Arqueología y Etnohistoria de la Puna Norte. También damos las gracias al personal de los distintos museos en 
donde se localizan las colecciones que hemos consultado en los últimos años, especialmente a los del Museo Etnográfico J. B. Ambrosetti (Universidad de Buenos Aires) y a los del Museo Etnográfico (Museos de la Cultura Mundial, Estocolmo, Suecia), cuyas piezas presentamos en esta oportunidad.

\section{Referencias citadas}

Alfaro de Lanzone, L. (1988). Excavación de la cuenca del rio Doncellas. Reconstrucción de una cultura olvidada en la Puna jujeña. San Salvador de Jujuy: Imprenta del Estado de la Provincia de Jujuy.

Alonso, R. (2010). Historia de la minería de Salta y Jujuy. Siglos XV-XX. Salta: Mundo Gráfico Salta Editorial.

Alonso, R. (2011). Queñoas, los raros árboles de la Puna en peligro de extinción. Gacetilla del Área de Minas, Año V(153), 46-47. Facultad de Ingeniería, Universidad Nacional de Jujuy, Argentina.

Andrews, J. (1967). Las provincias del norte en 1825. San Miguel de Tucumán: Universidad Nacional de Tucumán (Original de 1825).

Angiorama, C. (2001). De metales, minerales y yacimientos. Contribución al estudio de la metalurgia prehispánica en el extremo noroccidental de Argentina. Estudios Atacameños, 21, 63-87.

Angiorama, C. (2003). Producción y circulación de objetos de metal en la Quebrada de Humahuaca en momentos prehispánicos tardíos (900-1535 d.C.). Tesis doctoral. Facultad de Ciencias Naturales e Instituto Miguel Lillo, Universidad Nacional de Tucumán, Tucumán, Argentina.

Angiorama, C. (2005a). Acerca de Incas y metales en Humahuaca. Producción metalúrgica en Los Amarillos en tiempos del Tawantinsuyu. Relaciones de la Sociedad Argentina de Antropología, XXIX, 39-58.

Angiorama, C. (2005b). Nuevas evidencias de actividades metalúrgicas pre-incaicas en la Quebrada de Humahuaca (Jujuy, Argentina). Anales del Museo de América, 13, 173-198.

Angiorama, C. (2006). ¿Mineros quebradeńos o altiplánicos? La circulación de metales y minerales en el extremo noroccidental de Argentina (1280 - 1535 A.D.). Intersecciones en Antropología, 7, 147-161.

Angiorama, C. (2011a). La ocupación del espacio en el sur de Pozuelos (Jujuy, Argentina) durante tiempos prehispánicos y coloniales. Estudios Sociales del NOA, 11, 125-142.

Angiorama, C. (2011b). Impacto de la conquista inca en la metalurgia de Los Amarillos (Quebrada de Humahuaca, Jujuy). Revista Andes, 22(1), 5-18.

Angiorama, C. y Becerra, M. F. (2010). Evidencias antiguas de minería y metalurgia en Pozuelos, Santo Domingo y Coyahuayma (Puna de Jujuy, Argentina). Boletín del Museo Chileno de Arte Precolombino, 15(1), 81-104.

Angiorama, C., y Becerra, M. F. (2012). El oro de la Puna: lavaderos, socavones y mineros en el período colonial. Arqueología de la minería aurífera del extremo norte de la Puna de Jujuy (Argentina). Revista Vestigios, Revista Latino-Americana de Arqueología Histórica, 6(1), 50-80.

Angiorama, C., y Becerra, M. F. (2014). “Como en ella jamás ha habido minas...” Minería y metalurgia en la Puna de Jujuy durante momentos prehispánicos tardíos. Revista Relaciones de la Sociedad Argentina de Antropologia, XXXIX(2), 313-332. 
Angiorama, C., Becerra, M. F., Giusta, M. y Pérez Pieroni, M. J. (2019). Minería aurífera en el Noroeste argentino: el caso de Timón Cruz (Santa Catalina, Jujuy, Argentina). Revista de Arqueología Histórica Argentina y Latinoamericana, 13(2), 1-24.

Angiorama, C., Pérez Pieroni, M. J. y Becerra, M. F. (2017). Moreta, "pueblo de yndios chichas y tambo del ynga” (Puna de Jujuy, Argentina). Estudios Atacameños. Arqueología y Antropología Surandinas, 55, 163-181.

Basilico, S. (1992). Pueblo Viejo de La Cueva (Dto. de Humahuaca, Jujuy). Resultados de las excavaciones en un sector del asentamiento. Cuadernos de la Facultad de Humanidades y Ciencias Sociales, Universidad Nacional de Jujuy, 3, 108-127.

Becerra, M. F. (2014). Para que “creciera el pueblo como Potosí”: la minería en la Puna de Jujuy durante el período colonial. Estudios Atacameños. Arqueología y Antropología Surandinas, 48, 55-70.

Becerra, M. F., Angiorama, C. y Plaza Calonge, T. (2020). Evidencias de producción y uso de piezas de metal en la Puna de Jujuy: el aporte de las colecciones y los nuevos trabajos de campo. Estudios Sociales del NOA, 21, 111-141.

Besom, T. (2010). Inka sacrifice and the mummy of Salinas Grandes. Latin America Antiquity, 21(4), 399422.

Boman, E. (1908). Antiquités de la Région Andine de la République Argentine et du désert D’Atacama. París: Mission Scientifique.

Boman, E. (1918). Una momia de Salinas Grandes. Anales de la Sociedad Cientifica Argentina, LXXXV, 94-102.

Brackebusch, L. (1981). Por los Caminos del Norte. Tucumán, Argentina: Colegio de Graduados en Ciencias Geológicas de Tucumán (Original de 1883).

Cabanettes, C. y Amans, L. (1891). Memoria de la expedición por las regiones auriferas del norte de la provincia de Jujui emprendida por la comisión nombrada por el Superior Gobierno de la Nación en abril de 1891. Buenos Aires: Imp. y Librería de Mayo.

Cabrera Á. (1994). Regiones fitogeográficas argentinas. En W. F. Kugler (Ed.). Enciclopedia argentina de agricultura y jardinería. Tomo 2 (pp. 1-85). Buenos Aires: Acme.

Catalano, E. (2004). Antecedentes y estructura histórica de la minería argentina. En Lavandaio, E. y Catalano, E. (Eds.). Historia de la minería argentina, Tomo I (pp. 1-176). Buenos Aires: Segemar.

Cigliano, E. (1967). Investigaciones Antropológicas en el Yacimiento de Juella (Dep. de Tilcara, Provincia de Jujuy). Revista del Museo de La Plata (NS), Sección Antropología, VI, 123-249.

Coira, B., Caffe, P., Ramírez, A., Chayle, W., Díaz, A., Rosas, S., Pérez, A., Pérez, B., Orozco, O. y Martínez, M. (2004). Hoja Geológica 2366-I/2166-III, Mina Pirquitas. Boletín 269. Buenos Aires: Segemar.

Cruz, P. (2009). Huacas olvidadas y cerros santos. Apuntes metodológicos sobre la cartografía sagrada en los Andes del Sur de Bolivia. Estudios Atacameños. Arqueología y Antropología Surandinas, 38, 55-74.

Cruz, P. (2010). Monte adentro. Aproximaciones sobre la ocupación prehispánica de la serranía de Calilegua (prov. de Jujuy). Intersecciones en Antropología, 11(1), 129-144. 
Ferreiro, J. P. (2015). Jujuy en el espacio peruano. Una aproximación desde la teoría del lugar central. Cuadernos de la Facultad de Humanidades y Ciencias Sociales, Universidad Nacional de Jujuy, 48, 103-125.

Figueroa, V., Mille, B., Salazar, D., Berenguer, J., Menzies, A., Sapiains, P., Cifuentes, A. y Joly, D. (2018). A major prehispanic copper production center identified at Collahuasi, Southern Tarapacá altiplano (Chile). Chungara. Revista de Antropología Chilena, 50(4), 557-575. doi: 10.4067/S0717-73562018005001001.

Garrido, F. (2017). Comunidades mineras prehispánicas de pequeña escala y sus ventajas económicas y logísticas derivadas de su conectividad con el Qhapaq Ñan, desierto de Atacama, norte de Chile. Boletín de Antropología, 30(54), 48-74. Universidad de Antioquia, Medellín. doi:10.17533/udea.boan.v32n54a04.

González, A. R. (1983). Las provincias Incas del Antiguo Tucumán. Revista del Museo Nacional, 46, 317380 .

González, L. (1997). Cuerpos ardientes. Interacción surandina y tecnología metalúrgica. Estudios Atacameños, 14, 189-210.

González, L. (2004). Bronces sin nombre. La metalurgia prehispánica en el Noroeste Argentino. Buenos Aires, Argentina: Fundación Ceppa.

Hóskold, H. (1889). Memoria general y especial sobre las minas, metalurgia, leyes de minas, recursos de ventajas, etc. de la explotación de minas en la República Argentina. Buenos Aires: Courrier de La Plata.

Jutorán, A. (1958). Manifestaciones auriferas en los departamentos de Cochinoca y Rinconada (Provincia de Jujuy). Buenos Aires, Argentina: Informes inéditos de la Dirección Nacional de Geología y Minería. Carpeta No398. Biblioteca Segemar.

Krapovickas, P. y Aleksandrowicz, S. (1986-1987). Breve visión de la cultura de Yavi. Anales de Arqueología y Etnologia, 41-42, 83-127.

Lafone Quevedo, S. (2010). Relación Histórico-Descriptiva del Mineral de Las Capillitas y de sus Injenios en Andalgalá (provincia de Catamarca). En Caro, R. Escritos económicos (pp. 132-143). Catamarca: Universidad Nacional de Catamarca (Original de 1894).

Lapido, O. y Gabaldón V. (Dirs.). (1998). Estudio geológico integrado de la Quebrada de Humahuaca. Geologia regional y geomorfologí. Jujuy: Segemar e ITGE.

Lechtman, H. (1976). A Metallurgical Site Survey in the Peruvian Andes. Journal of Field Archaeology, 3(1), $1-42$.

Lechtman H. (1984). Andean Value Systems and the Development of Prehistoric Metallurgy. Technology and Culture, 25(1), 1-36.

Lechtman, H., Cruz, P., Macfarlane, A. y Carter, S. (2010). Procesamiento de metales durante el Horizonte Medio en el Altiplano Surandino (Escaramayu, Pulacayo, Potosí, Bolivia). Boletín del Museo Chileno de Arte Precolombino, 15(2), 9-27.

López, G., Coloca, F., Rosenbusch, M. y Solá, P. (2018). Mining, macro-regional interaction and ritual practices in the South-Central Andes: the first evidence for turquoise exploitation from the late prehispanic and inca periods in north-western Argentina (Cueva Inca Viejo, puna of Salta). Journal of Archaeological Science Reports, 17, 81-92. 
Mayer, E. (1986). Armas y herramientas de metal prehispánicas en Argentina y Chile. München: Materialien zur Allgemeinen und Vergleichenden Archaäologie. Band 38, Verlag C.H. Beck.

Méndez, V. (1999). Historia del Desarrollo minero argentino. En Recursos Minerales de la República Argentina (pp. 5-25). Buenos Aires: Anales 35, Segemar.

Nielsen, A. (1998). Impacto y organización del dominio Inka en Humahuaca (Jujuy, Argentina). Ms.

Nielsen, A., Angiorama, C., Maryañski, J., Ávila, F. y López, L. (2015). Paisajes prehispánicos tardíos en San Juan Mayo (frontera Argentina-Bolivia). Revista Arqueología, 21, 33-65.

Nordenskiöld, E. (1903). Travels on the boundaries of Bolivia and Argentina. The Geographical Journal, 21 (5), 510-525.

Ortiz, G. (2013). Vida y Muerte en el valle de San Francisco. Prácticas funerarias complejas y diversidad mortuoria en grupos de la selva pedemontana de Jujuy (Argentina). Revista Brasileira de História das Religiōes, Edição Especial, 93-117.

Otero, C. (2013). Producción, usos y circulación de bienes en el Pucará de Tilcara (Quebrada de Humahuaca, Jujuy). Tesis doctoral. FFyL, Universidad de Buenos Aires, Argentina.

Otero, C. y Tarragó, M. (2017). Reconstructing Inca socioeconomic organization through biography analyses of residential houses and workshops of Pucara de Tilcara (Quebrada de Humahuaca, Argentine). Journal of Anthropology and Archaeology, 5(1), 55-72.

Pereyra, F. (2008). Ecoregiones de la provincia de Jujuy. En B. Coira y E. Zappettini (Eds.). Relatorio del XVII Congreso Geológico Argentino. Geología y recursos naturales de la provincia de Jujuy (pp. 474-480). Jujuy: Talleres Gráficos DEL SRL.

Pérez, S. (2006-2007). Los metales de la 'Colección Doncellas' y el proceso de producción metalúrgico. Cuadernos del Instituto Nacional de Antropología y Pensamiento Latinoamericano, 21, 191-202.

Pérez Pieroni, J. (2015). Prácticas productivas y tradiciones tecnológicas: la manufactura cerámica prehispánica tardía y colonial en la cuenca sur de Pozuelos y el área de Santa Catalina, Puna de Jujuy, Argentina. Relaciones de la Sociedad Argentina de Antropología, XL(1), 13-44.

Raffino, R. (1978). La ocupación Inka en el N. O. Argentino: actualización y perspectivas. Relaciones de la Sociedad Argentina de Antropología, XII, 95-121.

Raffino, R., Alvis, R., Olivera, D. y Palma, J. (1986). La instalación Inka en la sección andina meridional de Bolivia y extremo boreal de Argentina. Comechingonia, Año 4, Número Especial, 63-131.

Salas, M. (1945). El antigal de Ciénaga Grande (Qda. de Purmamarca, Pcía. de Jujuy). Publicaciones del Museo Etnográfico, Serie A, V. Facultad de Filosofía y Letras, Universidad de Buenos Aires, Buenos Aires.

Salazar, D. (2003-2004). Arqueología de la minería: propuesta de un marco teórico. Revista Chilena de Antropologia, 17, 125-150.

Salazar, D., Berenguer, J. y Vega, G. (2013). Paisajes minero-metalúrgicos incaicos en Atacama y el Altiplano Sur. Chungara. Revista de Antropología Chilena, 45(1), 83-103.

Salazar, D. y Vilches, F. (2014). La arqueología de la minería en el centro-surandino: Balance y perspectivas. Estudios Atacameños. Arqueología y Antropología Surandinas, 48, 5-21. 
Scattolin, C., Bugliani, M. F., Cortés, L., Pereyra Domingorena, L. y Calo, M. (2010). Una máscara de cobre de tres mil años. Estudios arqueometalúrgicos y comparaciones regionales. Boletín del Museo Chileno de Arte Precolombino, 15(1), 25-46.

Sgrosso, P. (1943). Contribución al conocimiento de la minería y geología del NOA. Buenos Aires: Boletín 53, Ministerio de Agricultura de la Nación.

Spina, J., Giovanetti, M. y Ferraris, M. (2017). Interrogantes de la metalurgia prehispánica andina. Nuevas propuestas desde los hornos de Quillay (Catamarca, Argentina). Chungara. Revista de Antropologia Chilena, 49(3), 327-342.

Sureda, R., Ruiz, T. V., Ramírez, A. y Quiroga, A. (2008). Minerales de la provincia de Jujuy. En Coira, B. y Zappettini, E. (Eds.). Relatorio del XVII Congreso Geológico Argentino. Geología y recursos naturales de la provincia de Jujuy (pp. 606-624). Jujuy: Talleres Gráficos Del.

Taboada, C. (2005). Propuesta metodológica para el análisis diacrónico de arquitectura prehispánica y la asignación de significado conductual discriminado. Aplicación en el Noroeste Argentino. Anales del Museo de América, 13, 139-172.

Taboada, C. (2010). Evolución del grupo doméstico corresidente y lógica social en la construcción, remodelación y uso del espacio habitacional. Un análisis arqueológico para la Quebrada de Humahuaca. En Albeck, M., Scattolin, C. y Korstanje, A. (Eds.). El hábitat prehispánico. Arqueología de la arquitectura y de la construcción del espacio organizado (pp. 243-264). Jujuy: Universidad Nacional de Jujuy.

Tarragó, M. (1992). Áreas de actividad y formación del sitio de Tilcara. Cuadernos de la Facultad de Humanidades y Ciencias Sociales, 3, 64-74. Universidad Nacional de Jujuy.

Tarragó, M. y González, L. (1998). La producción metalúrgica prehispánica en el asentamiento de Tilcara (Prov. de Jujuy). Estudios preliminares sobre nuevas evidencias. En Cremonte, B. (Comp.). Las sociedades locales y sus territorios (179-198). Jujuy: Universidad Nacional de Jujuy.

Vetter, L., Casagrande, S., Vásquez, Y. y Fulle, M. (2008). Los hornos metalúrgicos del sitio Inca de Curamba (Perú): estudio por DRX. Espectroscopia Mössbauer y datación por métodos de luminiscencia. Bulletin de l'Institut Français d'Études Andines, 37(3), 451-475.

Von Rosen, E. (1957). Un mundo que se va. Exploraciones y aventuras entre las altas cumbres de la Cordillera de los Andes. Stubbe, C. F. (Trad.). San Miguel de Tucumán: Instituto Miguel Lillo (Original de 1919).

Zaburlín, M. (2014). Uso, consumo y circulación de vasijas cerámicas en los pueblos prehispánicos de la Cuenca de la Laguna de Guayatayoc (Puna de Jujuy). Tesis doctoral. Facultad de Ciencias Naturales e Instituto Miguel Lillo, Universidad Nacional de Tucumán, Tucumán, Argentina.

Zagorodny, N., Angiorama, C., Becerra, M. F. y Pérez Pieroni, M. J. (2015). Evidencias de actividades metalúrgicas en el sitio Campo de Carrizal (Belén, Catamarca). Intersecciones en Antropología, 16(3), 439-450.

Zappettini, E. (2004). Oro en la provincia de Jujuy. En Lavandaio, E. y Catalano, E. (Eds.). Historia de la Minería Argentina. Tomo II (pp. 69-75). Buenos Aires: Segemar. 